Review

\title{
Proximal Remote Sensing Buggies and Potential Applications for Field-Based Phenotyping
}

\author{
David Deery ${ }^{1, *}$, Jose Jimenez-Berni ${ }^{1}$, Hamlyn Jones ${ }^{2,3}$, Xavier Sirault ${ }^{1}$ and Robert Furbank ${ }^{1}$ \\ ${ }^{1}$ High Resolution Plant Phenomics Centre, Australian Plant Phenomics Facility, CSIRO Plant Industry, \\ GPO Box 1600, Canberra, ACT 2601, Australia; E-Mails: jose.jimenez-berni@ csiro.au (J.J.-B.); \\ xavier.sirault@csiro.au (X.S.); robert.furbank@csiro.au (R.F.) \\ ${ }^{2}$ Plant Science Division, College of Life Sciences, University of Dundee at The James Hutton Institute, \\ Invergowrie, Dundee DD2 5DA, Scotland, UK; E-Mail: h.g.jones@dundee.ac.uk \\ ${ }^{3}$ School of Plant Biology, University of Western Australia, Crawley, WA 6009, Australia \\ * Author to whom correspondence should be addressed; E-Mail: david.deery@csiro.au; \\ Tel: +61-2-6246-4869; Fax: +61-2-6246-4975.
}

Received: 10 March 2014; in revised form: 23 May 2014 / Accepted: 30 May 2014 /

Published: 10 July 2014

\begin{abstract}
The achievements made in genomic technology in recent decades are yet to be matched by fast and accurate crop phenotyping methods. Such crop phenotyping methods are required for crop improvement efforts to meet expected demand for food and fibre in the future. This review evaluates the role of proximal remote sensing buggies for field-based phenotyping with a particular focus on the application of currently available sensor technology for large-scale field phenotyping. To illustrate the potential for the development of high throughput phenotyping techniques, a case study is presented with sample data sets obtained from a ground-based proximal remote sensing buggy mounted with the following sensors: LiDAR, RGB camera, thermal infra-red camera and imaging spectroradiometer. The development of such techniques for routine deployment in commercial-scale breeding and pre-breeding operations will require a multidisciplinary approach to leverage the recent technological advances realised in computer science, image analysis, proximal remote sensing and robotics.
\end{abstract}

Keywords: LiDAR; time of flight; hyperspectral; RGB camera; thermal imaging; chlorophyll fluorescence; image analysis; data processing; field experiments; wheat 


\section{Introduction}

For crop improvement efforts to meet the expected requirement for increased crop yield potential in the coming decades [1-3], crop scientists and breeders will need to connect phenotype to genotype with high efficiency [4]. This connection has been partly facilitated through tremendous gains in biotechnology, including marker-assisted selection, association mapping and the increasing availability of low-cost DNA sequence information [5]. However, the biotechnology advances have not been matched by complementary methods to effectively and efficiently phenotype at the crop scale. Today, field phenotyping of complex traits associated with biomass development and yield is a laborious process, often involving destructive measurements taken from a subsection of the experimental plot, which may not accurately represent the entire plot and can be subject to individual human operator error. While standard protocols for crop phenotyping in wheat are available [6,7], the measurements are expensive, due to the labour requirement and, hence, seldom used by commercial breeding companies who are financially constrained. Moreover, field evaluation of germplasm for complex traits is challenging, since field environments are variable in time and space.

The limited availability of field-based high-throughput phenotyping methods has impeded progress in crop genetic improvement [8,9], though recent reviews [9-12] have highlighted the opportunities now available through sensor technology and the digital age. In this review, we evaluate the role of proximal remote sensing buggies for field-based phenotyping and present a case study to explore the possible traits that can be quantified, where proximal remote sensing is the deployment of sensors on a ground-based platform, in contrast to the remote deployment of sensors using aerial or satellite platforms [13].

\section{Field Phenotyping Platforms: The Role of Field Buggies}

A number of recent papers have reviewed approaches to phenotyping [14-16] largely concentrating on opportunities in controlled environments. Measurements in the field, however, are much more likely to be of use in the selection of genotypes that will perform well in farming practice, particularly where large plots that simulate real farm conditions are used [17]. Large plots require large areas of land for screening the large number of genotypes required for traditional breeding programmes, and effective approaches need to have the capacity to study such large areas.

\subsection{Approaches Available}

Approaches available for field phenotyping are diverse (see Table 1), ranging from hand-held point sensors, such as spectroradiometers, or thermal sensors [18-20], or imagers [21,22], sensors mounted on in-field fixed or mobile platforms, to sensors on unmanned aerial vehicles (UAVs), tethered balloons and manned aircraft [23-30]. Unfortunately, ad hoc hand-held measurements are not very useful for the high throughput required for the effective phenotyping of large field trials with many replicates, as they tend to be excessively labour intensive and time consuming, so alternatives are of particular interest. Fixed systems include those where a set of cameras can be automatically moved over a fixed field array: examples include the Lemnatec Field Scanalyzer [31] and the Eidgenössische Technische Hochschule (ETH) Zürich's Field Phenotyping Platform (FIP), comprising suspending cameras from four 24 m-high 
poles over an area of $130 \times 100 \mathrm{~m}$ [32]. Similarly, other fixed or semi-fixed platforms, such as "cherry pickers" and fixed towers are available that allow imagers to be raised substantially above the field to permit the observation of significant areas of crop within individual images [21,22,33]. The advantages include the ability to make a relative comparison between experimental units and to study large areas simultaneously (i.e., minimising problems caused by variation in radiation as irradiance changes with the passage of clouds). On the other hand, problems can be caused by an oblique view angle, including: difficulty in identifying individual plots; plots further away are both smaller and have more atmosphere to traverse, which may be important for thermal data; and the fact that the bidirectional reflectance factor (BRDF) varies both at different observation angles and also different solar elevations. Towers or cherry pickers generally need frequent moving to be able to cover an adequate area, which can be inconvenient. The use of airborne and UAV-mounted sensors are discussed in other articles; here, we concentrate on the use of mobile field platforms.

\subsubsection{Mobile Field Platforms ("Buggies")}

(a) The simplest approach that provides rigorous and constant observation geometry is to mount sensors on a light, hand-controlled cart; for example, a simple hand-pushed frame on bicycle wheels ( $2 \mathrm{~m}$-wide by $1.2 \mathrm{~m}$-long and with a 1-m clearance) has been described [34]. Such systems can be very cheap and permit the mounting of a wide range of sensors and associated recording equipment. In principle, it should also be possible to tag recordings to individual plots using high precision GPS.

(b) The next step of sophistication is to incorporate drive mechanisms and autonomous control to allow the system to traverse the field automatically at a steady rate, without the need to be pushed (which can lead to crop trampling). A wide range of such systems of varying degrees of sophistication have been developed, including the "BoniRob" platform from Osnabrucke, Germany [35] and the "Armadillo" from Denmark and the University of Hohenheim [36]. BoniRob has a lighter, wheeled structure with adjustable ground clearance and configurable wheel spacing that is probably more suitable for taller crops.

(c) The next stage of development involves the use of larger and even more sophisticated platforms (or "buggies"), usually with a driver, that can support a wider range of sensors and controls. Some examples of such custom-designed devices for field phenotyping include the system designed in Maricopa (Arizona) described by [37], the "BreedVision" system from Osnabrucke [38,39] and the Avignon system [40] and the "Phenomobile" designed at the High Resolution Plant Phenomics facility in Canberra (described in the following Section 4.1 and Figure 1).

(d) There is also increasing convergence of such specialised "Phenomobiles" with the standard arrays of sensors commonly mounted on tractor booms for the routine monitoring of crop conditions, such as nitrogen status (e.g., Crop-Circle (Holland Scientific, Lincoln, Nebraska, USA), Yara-N sensor (Yara, Haninghof, Germany) and Greenseeker (Trimble Agriculture, Sunnyvale, California, USA)). 
Table 1. Phenotyping platforms and some relative advantages and disadvantages.

\begin{tabular}{|c|c|c|}
\hline Platform Type & Disadvantages & Advantages \\
\hline Fixed systems & Generally expensive; can only monitor a very limited number of plots & $\begin{array}{l}\text { Unmanned continuous operation; after-hours operation (e.g., } \\
\text { night-time); good repeatability }\end{array}$ \\
\hline $\begin{array}{l}\text { Permanent platforms based on cranes, } \\
\text { scaffolds or cable-guided cameras }\end{array}$ & Limited area of crop, so very small plots; expensive & Give precise, high resolution images from a fixed angle \\
\hline Towers/cherry-pickers & $\begin{array}{l}\text { Generally varying view angle; problems with distance (for thermal), } \\
\text { bi-directional reflectance distribution function (BRDF), plot delineation, } \\
\text { etc.; difficult to move, so limited areas covered }\end{array}$ & $\begin{array}{l}\text { Good for the simultaneous view of the area; can be moved to } \\
\text { view different areas }\end{array}$ \\
\hline Mobile in-field systems & $\begin{array}{l}\text { Generally take a long time to cover a field, so subject to } \\
\text { varying environmental conditions }\end{array}$ & $\begin{array}{l}\text { Very flexible deployment; good capacity for GPS/GIS tagging; } \\
\text { very good spatial resolution }\end{array}$ \\
\hline Hand-held sensors & $\begin{array}{l}\text { Very slow to cover a field; only one sensor at a time; } \\
\text { different operators can give different measurements }\end{array}$ & Good for monitoring \\
\hline Hand-pushed buggies & $\begin{array}{l}\text { Limited payload (weight); hard operation } \\
\text { for large experiments }\end{array}$ & $\begin{array}{l}\text { Relatively low cost; flexibility with payload and view angle geometry; } \\
\text { very adaptable }\end{array}$ \\
\hline Tractor-boom & Long boom may not be stable & $\begin{array}{l}\text { Easy operation; constant view angle; wide swath (if enough sensors } \\
\text { are mounted as on a spraying bar); mounting readily available } \\
\text { (needs modification) }\end{array}$ \\
\hline Manned buggies & Requires a dedicated vehicle (expensive) & $\begin{array}{l}\text { Flexibility with the design of the vehicle (e.g., tall crops, row spacing); } \\
\text { Constant view angle; very adaptable }\end{array}$ \\
\hline Autonomous robots & Expensive; no commercial solutions available; safety mechanisms required & $\begin{array}{l}\text { Unmanned continuous operation; after-hours operation (e.g., } \\
\text { night-time) }\end{array}$ \\
\hline Airborne & $\begin{array}{l}\text { Limitations on the weight of the payload depending on the platform; } \\
\text { a lack of turnkey systems; spatial resolution depends on speed and altitude }\end{array}$ & $\begin{array}{l}\text { Can cover the whole experiment in a very short time, getting a snapshot } \\
\text { of all of the plots without changes in the environmental conditions }\end{array}$ \\
\hline Blimps/balloons & $\begin{array}{l}\text { Limited to low wind speed; not very easily moved precisely; } \\
\text { limited payload }\end{array}$ & Relatively cheap compared with other aerial platforms \\
\hline UAVs & $\begin{array}{l}\text { Limited payload (weight and size); limited altitude (regulations) and total } \\
\text { flight time (hence, total covered area); less wind-affected than blimps; } \\
\text { regulatory issues depending on the country }\end{array}$ & $\begin{array}{l}\text { Relatively low cost compared with manned aerial platforms; } \\
\text { GPS navigation for accurate positioning }\end{array}$ \\
\hline Manned aircraft & $\begin{array}{l}\text { Cost of operation can be expensive and may prohibit repeated flights, } \\
\text { thereby reducing temporal resolution; problems of availability }\end{array}$ & $\begin{array}{l}\text { Flexibility with the payload (size and weight); } \\
\text { Can cover large areas rapidly }\end{array}$ \\
\hline
\end{tabular}


Figure 1. Components of the Phenomobile.

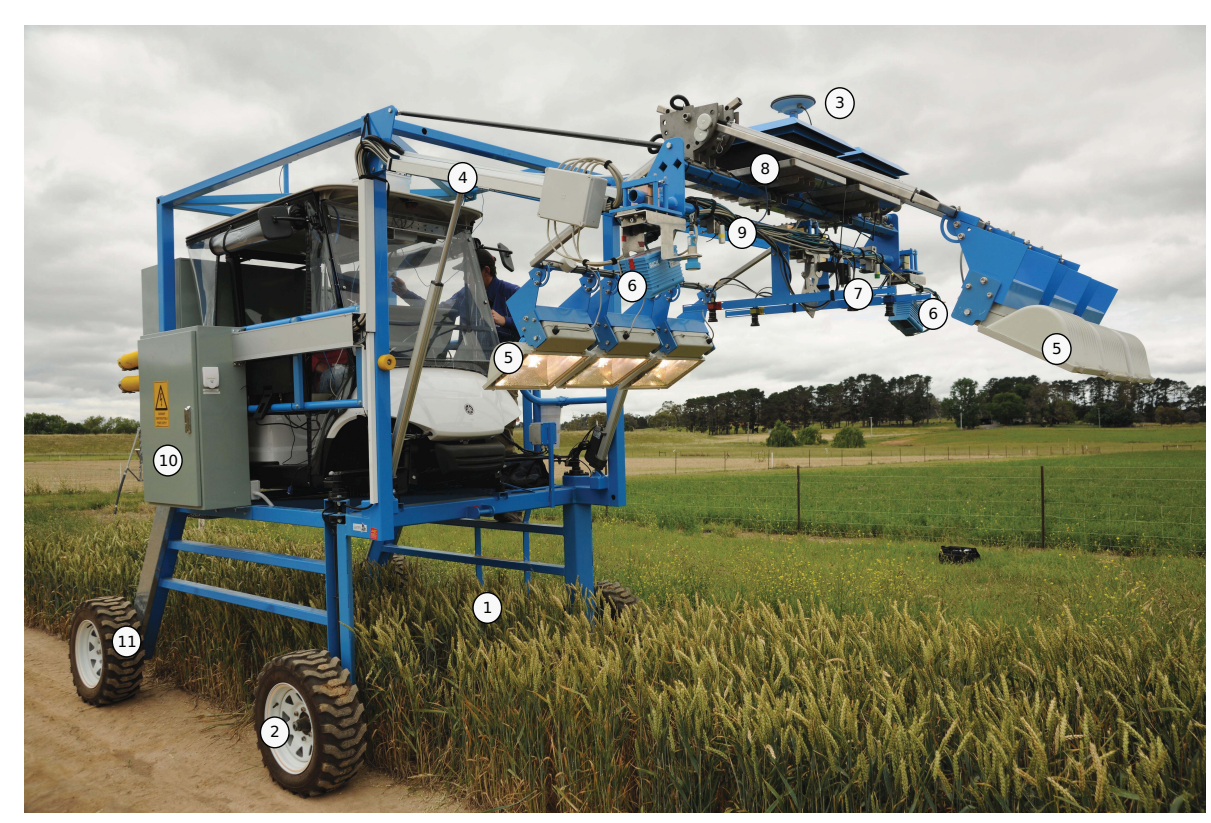

\begin{tabular}{|c|c|}
\hline & Description \\
\hline 1 & $\begin{array}{l}\text { Frame with } 1.5 \mathrm{~m} \\
\text { ground clearance }\end{array}$ \\
\hline 2 & $\begin{array}{l}\text { Wheel encoders } \\
\text { ( 1-mm accuracy) }\end{array}$ \\
\hline 3 & $\begin{array}{l}\text { Real time kinematic GPS } \\
(\sim 2 \text {-cm accuracy) }\end{array}$ \\
\hline 4 & $\begin{array}{l}\text { Height adjustable boom } \\
(\max 3 \mathrm{~m})\end{array}$ \\
\hline 5 & Removable light bank \\
\hline 6 & Three LiDAR sensors \\
\hline 7 & Four RGB stereo cameras \\
\hline 8 & $\begin{array}{l}\text { Spectrometer/ } \\
\text { hyperspectral camera }\end{array}$ \\
\hline 9 & $\begin{array}{l}\text { Infra-red thermometers/ } \\
\text { infra-red thermal camera }\end{array}$ \\
\hline 10 & Generator and electronics \\
\hline 11 & $\begin{array}{l}\text { Two wheel drive } \\
\text { hydraulic drive system }\end{array}$ \\
\hline
\end{tabular}

\subsubsection{Relative Advantages/Disadvantages of Different Platforms}

Table 1 summarises the advantages and disadvantages of different types of sensing systems used for field phenotyping. The high payload and great flexibility of buggies suggests that they are probably the most useful general approach.

\section{Phenotyping Sensors for Field Buggies}

A very wide range of sensors can be mounted on any of the various field buggies and other phenotyping platforms (for example, see Figure 1). A selection of possible sensors is listed in Table 2, and their applications are discussed below. Sensors may either be point sensors (such as spectroradiometers or thermal sensors) or imaging sensors that provide information on the spatial distribution of the property being detected. Two distinct modes of imaging sensors are available, which differ according to their method of data acquisition, namely: (i) frame imagers, where a 2D array of pixels is obtained at a single point in time (e.g., RGB camera); and (ii) line-scan imagers, where a single line of pixels is obtained at a single time point and the image is created from the movement of the buggy and by concatenating the individual lines of pixels. Line-scan imagers require the precise determination of the position and attitude of the sensor for each line collected in order to generate the image. This can be attained by using an accurate combination of GPS with inertial measurements units (IMU) or wheel odometry with wheel encoders. Therefore, rather different software solutions are required for the two types of imagers. Compared with non-imaging sensors, imaging sensors are much more widely applicable, as they allow the precise delineation of measurement areas in plots and, potentially, the elimination of background areas in images, though there is a greatly enhanced requirement for sophisticated image analysis software to achieve this. 
Table 2. Applications and limitations of common sensors mounted on field buggies.

\begin{tabular}{ll}
\hline Sensor Type & Applications \\
\hline RGB Cameras & $\begin{array}{l}\text { Imaging canopy cover and canopy colour. Colour information can be used } \\
\text { for deriving information about chlorophyll concentration through greenness } \\
\text { indices. The use of 3D stereo reconstruction from multiple cameras or } \\
\text { viewpoints allows the estimation of canopy architecture parameters. }\end{array}$ \\
\hline LiDAR and time of flight sensors & $\begin{array}{l}\text { Canopy height and canopy architecture in the case of imaging sensors } \\
\text { (e.g., LiDAR). Estimation of LAI, volume and biomass. Reflectance from } \\
\text { the laser can be used for retrieving spectral information (reflectance in } \\
\text { that wavelength). }\end{array}$ \\
\hline Spectral sensors & $\begin{array}{l}\text { Biochemical composition of the leaf/canopy. Pigment concentration, } \\
\text { water content, indirect measurement of biotic/abiotic stress. } \\
\text { Canopy architecture/LAI with NDVI. }\end{array}$
\end{tabular}

Fluorescence Photosynthetic status, indirect measurement of biotic/abiotic stress.

Photosynthetic status, indirect measurement of biotic/abiotic stress.

Limitations

No spectral calibration, only relative measurements. Shadows and changes in ambient light conditions can result in under- or over-exposure and limit automation of image processing.

Integration/synchronization with GPS and wheel encoder position systems is required for georeferencing.

Sensor calibration required. Changes in ambient light conditions influence signal and necessitate frequent white reference calibration. Canopy structure and camera/sun geometries influence signal. Data management is challenging.

Difficult to measure in the field at the canopy scale, because of the small signal-to-noise ratio, though laser-induced fluorescence transients (LIFT) can extend the range available, while solar-induced fluorescence can be used remotely.

Changes in ambient conditions lead to changes in canopy temperature, making a comparison through time difficult, necessitating the use of references. Difficult to separate soil temperature from plant temperature in sparse canopies, limiting the automation of image processing. Sensor calibration and atmospheric correction are often required. induction (EMI), ground penetrating radar (GPR) and electrical resistance 


\subsection{Types of Sensor}

\subsubsection{RGB Cameras}

Arguably, the most widely used sensor for most applications is the conventional RGB digital camera, which provides information on canopy cover and canopy colour [41-43]. Canopy cover estimates can readily be estimated automatically from nadir-view images using tools, such as "magic wand" or colour threshold, available in many image processing programmes, and hence are used to estimate also leaf area index (LAI) and light interception [44,45]. Estimates of LAI can be well estimated from images taken at an angle of $57.5^{\circ}$ [46]. Image analysis can also be used to extract more sophisticated information (e.g., on water stress) from shape, compactness, solidity, etc. [47]. Using a stereo camera rig or images from multiple locations [48,49] allows the detailed reconstruction of the canopy structure and its analysis to obtain critical variables for phenotyping, such as LAI, leaf area distribution or panicle length [50]. This photogrammetric approach can be easily applied to images obtained from a moving buggy, where consecutive images can be acquired at constant intervals over the canopy. The position and geometry of the images can be determined using the GPS location or wheel encoders.

\subsubsection{LiDAR and Time of Flight Sensors}

A number of other sensors can provide 3D structural information. Perhaps the best known and most widely used type of sensor for 3D canopy reconstruction is LiDAR [51-53]. Such laser systems have been used for rapid LAI mapping [54] and to estimate the plant area density profiles of a wheat canopy [55]. Simpler alternatives, though having rather lower spatial resolution or range than LiDAR, include depth cameras based on time-of-flight [56,57], ultrasonic sensors [37] and even consumer-grade gaming interfaces, such as the Microsoft Kinect [58], all of which have been used for the characterisation of different canopies $[52,59,60]$.

\subsubsection{Spectral Sensing}

A powerful optical remote sensing approach for canopy characterisation is to make use of the characteristic difference between the high reflectance of plant leaves in the near-infrared and the correspondingly low reflectance in the red; this enabled the development of the normalised difference vegetation index (NDVI) [61] and a wide range of related indices [42]. Such vegetation indices are particularly useful for quantifying vegetation cover where the sensor view is large (as with wide angle single sensors or with remote imagers with large pixels that contain a mixture of vegetation and background soil). In addition to providing information on canopy cover, these vegetation indices and others, such as the red-edge position, also provide information on leaf nitrogen or chlorophyll content. They have therefore been widely used for the evaluation of canopy nitrogen content for crop management purposes with a range of commercial sensors for mounting on tractor booms that were outlined above in Section 2.1.1.

More interesting for phenotyping, however, is the application of spectral reflectance to derive information on canopy biochemistry, such as the content of water and stem soluble carbohydrates, and of pigments, such as chlorophyll, carotenoids and xanthophylls. Although broadband multispectral 
sensors can be used, more accurate information can be obtained from narrow-band or hyperspectral sensors [30,62-65]. A wide range of techniques have been proposed and tested for the selection of the critical wave bands to use in the development of appropriate hyperspectral indices for different biochemicals and physiological processes. These include the use of 2D correlation plots [66], partial least squares regression [67,68], principal components analysis [65], support vector machines (SVM) [69], neural networks [70] and other machine learning approaches for stress detection. The power of many of these techniques can be enhanced by a combination with radiative transfer modelling [71,72], which allows one to correct for complexity introduced by shadowing and complex canopy structure.

Multispectral and hyperspectral measurements are widely used for the estimation of canopy water content as an indicator of water status. These make use of the water absorption bands in the infrared to describe various water indices [42,73-75]. Alternatively, a dual wavelength laser can be used to estimate an equivalent water thickness (EWT) [76], as it can be range-resolved to ignore the background soil, which might otherwise affect spectral EWT measurement. In addition to simple water indices, the use of high resolution spectroscopy and wavelet analysis [77-79] can also give a high sensitivity to canopy water content. Measurements of water content using spectral reflectance data have, on occasion, been successfully correlated with water potential [80,81], but as with any rather indirect proxy marker, the ability to predict water potential under a range of conditions or plant ages is likely to always be rather limited [82].

Hyperspectral reflectance indices can also be used as a probe for physiological function, such as for the rate of photosynthesis. The best known approach is the photochemical reflectance index (PRI) introduced by Gamon [83], which is based on a correlation between the epoxidation of xanthophylls and the assimilation rate, which can be quantified from the change in absorptance at $531 \mathrm{~nm}$.

A disadvantage with hyperspectral imagers is that they tend to be very expensive, though a number of relatively inexpensive multispectral imagers are becoming available that can be mounted on buggies or other phenotyping platforms, where specifically tailored narrow-band filters can be incorporated. The lower spatial resolution of the corresponding single view hyperspectral sensors, whose footprint may cover a whole plot, inevitably have a lower discriminatory power, because of the complications caused by canopy complexity and soil background. The conventional approach to the spectral analysis of images is based on a pixel-by-pixel analysis, with averages taken of the pixels within any class; an alternative approach that has been shown to have some advantages is to segment the available pixels into discrete objects prior to analysis, a technique known as "object-based image analysis" [4].

\subsubsection{Fluorescence}

In addition to the passive sensing of spectral reflectance, useful information can be obtained from an analysis of fluorescence from crops. The most useful information can be obtained from chlorophyll fluorescence, which is a powerful indicator of photosynthetic functioning. The use of modulated fluorescence (as widely used in the laboratory) requires substantial power for the rapid illumination pulses needed and is limited to situations where the sensor is within $1 \mathrm{~m}$ or so of the crop and probably has too high a power requirement for most mobile buggies. The pulse of rapid illumination must also uniformly illuminate all of the imaged crop canopy, and this may be difficult to achieve in the field. There are, however, two potentially useful alternative approaches: (i) laser-induced fluorescence 
transients (LIFT) [84]; and (ii) passive solar-induced fluorescence based on the infilling of radiation in the Fraunhofer lines in the solar spectrum [85-88]. Less precise estimates of green leaf area, chlorophyll content and photosynthesis can also be obtained using relatively simple canopy laser-induced fluorescence (CLIF) systems [89].

Fluorescence in the blue region (for example, using short-wave laser stimulation) might also possibly be a tool for the study of stress-induced compounds that could be screened as an indicator of stress responses. However, the power requirements of such active sensors may be limiting for field phenotyping applications.

\subsubsection{Thermal Sensors}

One of the most powerful tools for phenotyping, especially for traits related to water stress responses, is the use of thermal sensing or imaging [90]. The basis of the approach is that surfaces are cooled by evaporation, so their temperatures fall in proportion to the evaporation rate. Any stomatal closure in response to drought stress, therefore, will be manifest as a warmer temperature, so that thermal imaging can be used to quantify the stomatal closure. As with spectral reflectance sensing, a major problem with all thermal sensing is that posed by interference from the background, as soil temperature is commonly many degrees warmer than that of the transpiring canopy, and techniques are necessary to obtain a pure signal from the canopy only. These can include the overlaying of multispectral images and extracting shaded or sunlit canopy temperatures [91-93] or the use of thresholding [94]. Various automated or semi-automated methods have been proposed for canopy temperature extraction for different experimental plots [93,95].

Although straightforward in principle, to use thermal sensing, there are a number of potential difficulties with its practical application, in addition to the obvious problem caused by the high background temperature. Most important is the fact that surface temperature depends not only on the evaporation rate, but also on varying environmental factors, including the incoming solar radiation, the ambient air temperature and the wind speed (and hence, boundary layer conductance). The most usual way to correct for the rapidly changing environmental conditions is to normalise observations to the mean of nearby plot temperatures [22]. This approach is particularly suitable for tower-based images, where many plots are included in each image, but can be adapted to buggy use by normalising to running means, though the precision of this correction is best when many plots are included in each image [21,22]. Rigorous correction on the basis of the full canopy energy balance can also be achieved, where a full set of micrometeorological observations are available [96]. Other problems are related to the fact that varying angles between the view and solar illumination angles can lead to differing proportions of sunlit and shaded leaves being observed, with consequences for observed temperatures; such BRDF-based problems need to be recognised or corrected for on the basis of a canopy radiation transfer model. An interesting observation that may be related to differences in aerodynamic resistance is that there can be consistent differences in canopy temperature between tall and dwarf crops, irrespective of differences in stomatal conductance [97,98].

Thermal sensing has been used for many crops, from small grain cereals to maize [99] and fruit trees [100]. It has also been used in combination with spectral sensing for the enhanced estimation of leaf water content [101]. 


\subsubsection{Other Sensors}

A wide range of other sensors can, in principle, be mounted on buggies or other mobile platforms. These include radar (microwave) sensors for the measurement of soil moisture, while other sensors available for soil mapping include electromagnetic induction (EMI), ground penetrating radar (GPR) and electrical resistance tomography (ERT) [102]. Even radiation attenuation using a Gamma probe could give information on crop mass and water content, but this is unlikely to be acceptable in practice on health and safety grounds.

\subsection{Some Technical Challenges in the Use of Proximal Sensors Mounted on Buggies}

Major challenges with the use of sensors include:

(a) Problems resulting from mixed pixels when a single pixel comprises both plant material and background soil (Jones and Sirault, submitted to this special issue).

(b) Difficulties caused by variation in the solar illumination angle and the bi-directional reflectance distribution function (BRDF) (for example, the resulting variation in the amount of shadowing in a pixel and its dependence on canopy structure) [103].

(c) Although the simplest application of in-field remote sensing, especially of spectral reflectance, is to use simple vegetation indices (VI) as indicators of variables of interest (e.g., $\mathrm{N}$ or water content, chlorophyll, LAI or photosynthesis), the values of the quantities being estimated can be very subject to environmental conditions and to canopy structure; this leads to substantial imprecision in the estimates of variables of interest and the need for site-specific calibration [82]. However, substantial improvements can be made in the estimation of these fundamental variables, by taking into account the detailed canopy structure and BRDF and the use of appropriate radiation transfer models $[62,104,105]$. This approach often requires significant computing power and may not often be suitable for real-time implementation on a mobile buggy.

(d) Data handling. A particular and continuing challenge in the use of platform-mounted sensors remains the data handling and assimilation of data from different types of sensor (frame imagers, line-scan imagers, point sensor), each with their own scales of view, and their combination with GPS information to generate effective measurements for a particular experimental plot. This generally requires specialist software engineering skills.

\section{Application to Phenotyping}

Identification of appropriate target traits for phenotypic evaluation is of critical importance for breeders and physiologists. In cereals, traits that contribute to the components that make up the conceptual framework of yield potential in the target environment under the limitation of water [106] or radiation [107] are of interest. Such traits have been identified previously for crops growing under water [108-110] or radiation [111] limitation. A summary of sensor quantifiable cereal traits and their primary effect contributing to yield is presented in Table 3, together with the relevant sensor technology that can be mounted on a field buggy for phenotyping. While the traits identified in Table 3 contribute to yield, new cereal varieties released by commercial breeding programs must meet disease resistance 
and quality criteria in the harvestable product to satisfy market requirements. Indeed, many commercial wheat breeding operations in Australia preferentially focus on the selection for disease resistance, quality and then yield, presumably because of the phenotyping challenges associated with the direct selection of traits in Table 3.

Table 3. The summary of cereal traits quantifiable with sensors mounted on field buggies and the primary effect contributing to yield.

\begin{tabular}{|c|c|c|}
\hline Trait & Primary Effect & Sensor Technology \\
\hline \multicolumn{3}{|l|}{ Canopy structure } \\
\hline Leaf area index & RI & $\begin{array}{l}\text { LiDAR, 2D and 3D RGB photogrammetry, } \\
\text { ToF camera, spectral vegetation indices }\end{array}$ \\
\hline Biomass & WUE/RUE & LiDAR, 2D and 3D RGB photogrammetry, ToF camera \\
\hline Tillering & HI & LiDAR, 2D and 3D RGB photogrammetry, ToF camera \\
\hline Canopy height & WUE/HI & LiDAR, 2D and 3D RGB photogrammetry, ToF camera \\
\hline Awn presence & WUE/HI & LiDAR, 2D and 3D RGB photogrammetry, ToF camera \\
\hline Leaf rolling & WUE/RI & LiDAR, 3D RGB photogrammetry and ToF camera \\
\hline Leaf angle & RI & LiDAR, 3D RGB photogrammetry and ToF camera \\
\hline Early vigour & WUE/WU & LiDAR, 2D RGB photogrammetry, spectral vegetation indices \\
\hline Tissue damage & WU/RI & RGB camera, multi/hyperspectral camera \\
\hline Leaf glaucousness/waxes & WUE/HI & Multi/hyperspectral camera \\
\hline Pubescence & WUE/HI & Multi/hyperspectral camera \\
\hline Grain fertility (number) & $\mathrm{HI}$ & Very high resolution RGB images \\
\hline \multicolumn{3}{|l|}{ Function } \\
\hline Water loss/stomatal control & WUE/WU & Thermal camera, infra-red temperature sensor \\
\hline Photosynthesis & RUE & $\begin{array}{l}\text { Chlorophyll fluorescence, LIFT, PRI, estimation from } \\
\text { biomass accumulation (see above) }\end{array}$ \\
\hline \multicolumn{3}{|l|}{ Phenology } \\
\hline Stay green/senescence & HI/RI & LiDAR, multi/hyperspectral camera, thermal camera \\
\hline Flowering date & HI & LiDAR, high resolution RGB images \\
\hline \multicolumn{3}{|l|}{ Biochemistry } \\
\hline Stem carbohydrates & HI & hyperspectral camera \\
\hline Nutrient content (e.g., N) & NUE & Multi/hyperspectral camera \\
\hline $\begin{array}{l}\text { Carotenoids, xanthophylls, } \\
\text { anthocyanins, water indices }\end{array}$ & WU/RI & Multi/hyperspectral camera \\
\hline
\end{tabular}

$\mathrm{HI}=$ harvest index; LIFT = laser-induced fluorescence transients; NUE = nitrogen-use efficiency;

$\mathrm{PRI}=$ photochemical reflectance index; $\mathrm{RGB}=$ red, green and blue; $\mathrm{RI}=$ radiation interception; RUE = radiation-use efficiency; ToF = time of flight; $\mathrm{WU}=$ water-use; WUE = water-use efficiency. 


\subsection{Case Study}

The Phenomobile developed at the High Resolution Plant Phenomics Centre, Canberra (Figure 1), comprises a height adjustable sensor bar ( $\max 3 \mathrm{~m}$ ), a two-wheel drive hydraulic drive system, a 6-kW generator, RTK GPS ( $\sim 2 \mathrm{~cm}$ resolution), wheel encoders on both front wheels ( $\sim 1 \mathrm{~mm}$ resolution) and a removable light bank. The frame of the Phenomobile itself was designed to traverse a mature wheat crop (1.2-m ground clearance) and the wheel width designed to match that of the equipment used to sow the trials, thereby minimising the chance of encroachment into the experimental plot during measurement. Thus, the Phenomobile can traverse $\sim 1.8$-m width plots of a mature wheat crop without disturbing the canopy at a typical operating speed of $1 \mathrm{~m} / \mathrm{s}$.

The height adjustable sensor bar can accommodate a range of sensors, including: three LiDAR sensors, four high resolution RGB cameras, a thermal infra-red camera, three infra-red thermometers, a full range spectroradiometer and a hyperspectral camera. Sample data sets from these sensors are discussed in the below section within the context of the development of high-throughput phenotyping techniques.

\subsubsection{LiDAR Subsystem}

The LiDAR subsystem used on the Phenomobile presents possibilities for using time of flight, resolved distance, and signal intensity information to extract canopy structural parameters that are traditionally measured either manually using destructive sampling or simply estimated by a visual score. The LiDAR sensor (LMS400, 70 FOV, SICK AG, Waldkirch, Germany) used on the Phenomobile comprises a monochromatic red laser light source. The active nature of the LiDAR confers a number of advantages when compared to the traditional RGB camera, including: the LiDAR is not influenced by shadows and changes in the ambient light conditions, while the RGB camera requires parameterization for each light condition; the LiDAR can obtain measurements under all light conditions in contrast to an RGB camera that requires an additional light source in low-light conditions.

The LiDAR intensity signal provides high contrast between soil and green vegetation, as a greater proportion of the red laser is absorbed by green vegetation than soil. The high contrast between plant and soil achieved from the LiDAR intensity image is highly amenable for image analysis to derive ground cover estimation and possibly plant seedling counts. This is illustrated in the comparison of an RGB image and a LiDAR intensity image of the same scene (Figure 2).

The high resolution of the height data obtained from the LiDAR is amenable to the estimation of advanced canopy structural parameters, like leaf angular distribution. From the LiDAR height image of a mixed plot of forage Brassica (Brassica napus) and maize (Zea mays), two transects have been made in the image to derive the height profiles (Figure 3) across the width of the plot and for a single maize leaf. The height profile of the single maize leaf illustrates the possibility for the non-destructive estimation of leaf angle.

The time of flight returns from the LiDAR can be used to measure the height of the crop canopy. This is illustrated in Figure 4 with the height profile of five genotypes varying for canopy height. The two profiles show a single-pixel profile and the average height of the plot. 
Figure 2. Comparison of an RGB image (a) and the intensity image from the LiDAR (b), both acquired over the same plot of rice. The weeds and shadowing in the RGB image present a clear difficulty for the automatic extraction of the fractional cover, while the use of an active sensor, such as the red laser from the LiDAR, yields high contrast between soil and plants and can even discriminate between species based on the intensity or pattern of the reflectance.

a)

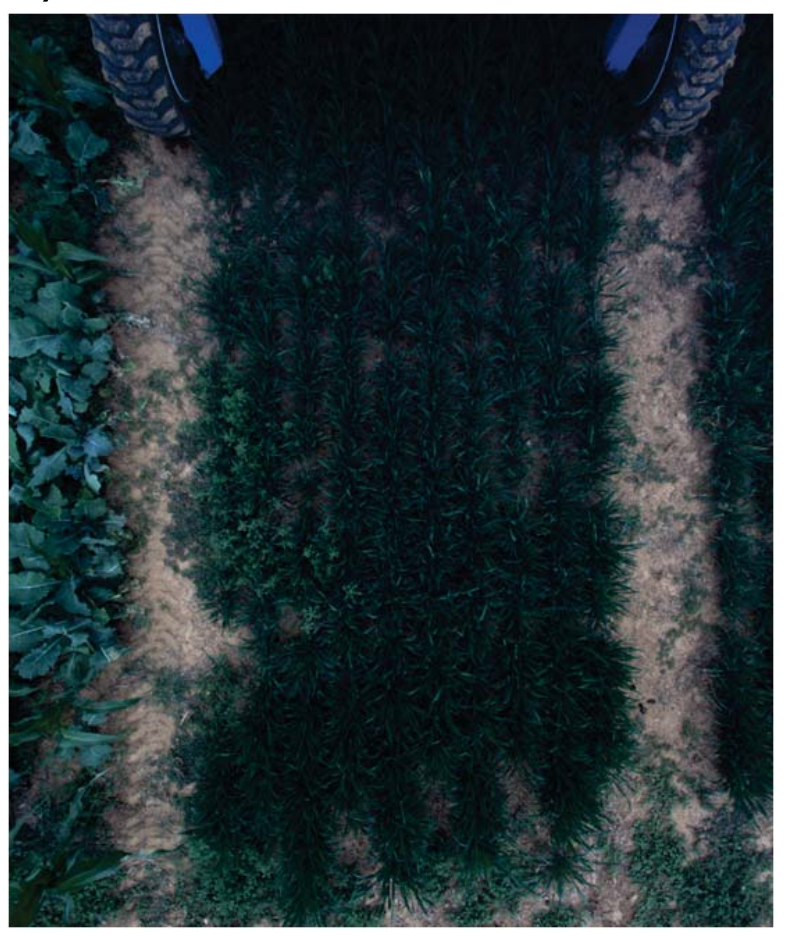

b)

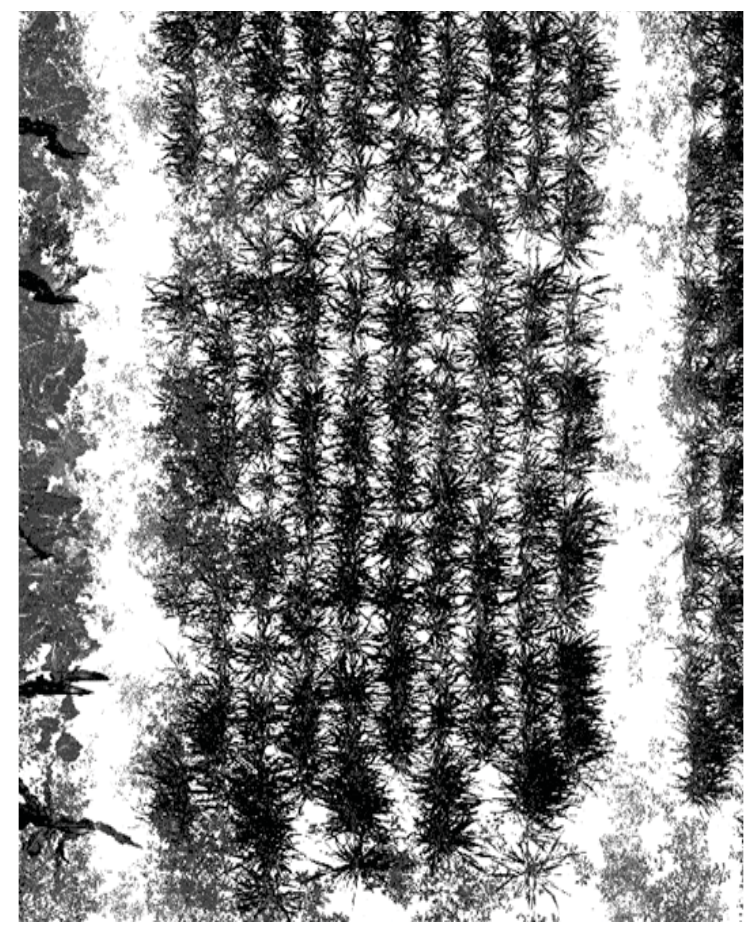

For an experiment comprising wheat genotypes varying for height, we compared the crop canopy height measured manually with a ruler to the height extracted from the LiDAR data (Figure 5). The manual measurements were obtained from one height measurement per $6 \mathrm{~m}$ by $2 \mathrm{~m}$ experimental plot; while the LiDAR height measurements were obtained from the mean of the top 95th percentile of the height distribution for a given experimental plot minus the height of the ground obtained from the average of the returns from the soil. An $R^{2}$ relationship of 0.86 was obtained between both measurements with a root mean square error ( $R M S E)$ of $78.93 \mathrm{~mm}$. Interestingly, for shorter canopy height measurements, the LiDAR gave higher values than the manual measurement, while for taller canopy height measurements, the LiDAR gave lower values than the manual measurement. The possible explanation for this bias is that the manual measurements only sample one or two points of the plot using the ruler, which in the case of non-uniform plots with a mix of tall and shorter plants could lead to a bias in manual measurements.

The possibility to identify individual plant organs from the height image obtained from the LiDAR is illustrated in Figure 6, where the spikes of a mature wheat crop are visible and have been segmented. The segmentation of the canopy height and intensity images by depth could be used to further enhance the contrast required for feature extraction of individual plant organs using image analysis algorithms. 
Figure 3. LiDAR data acquired over a mixed plot of forage Brassica and maize. (a) Depth image rasterized from the LiDAR height data; (b) height profile across the plot (A-B line in red); (c) height profile of a single maize leaf ( $\mathrm{C}-\mathrm{D}$ blue line) illustrating the potential to measure the leaf angle non-destructively.

a)

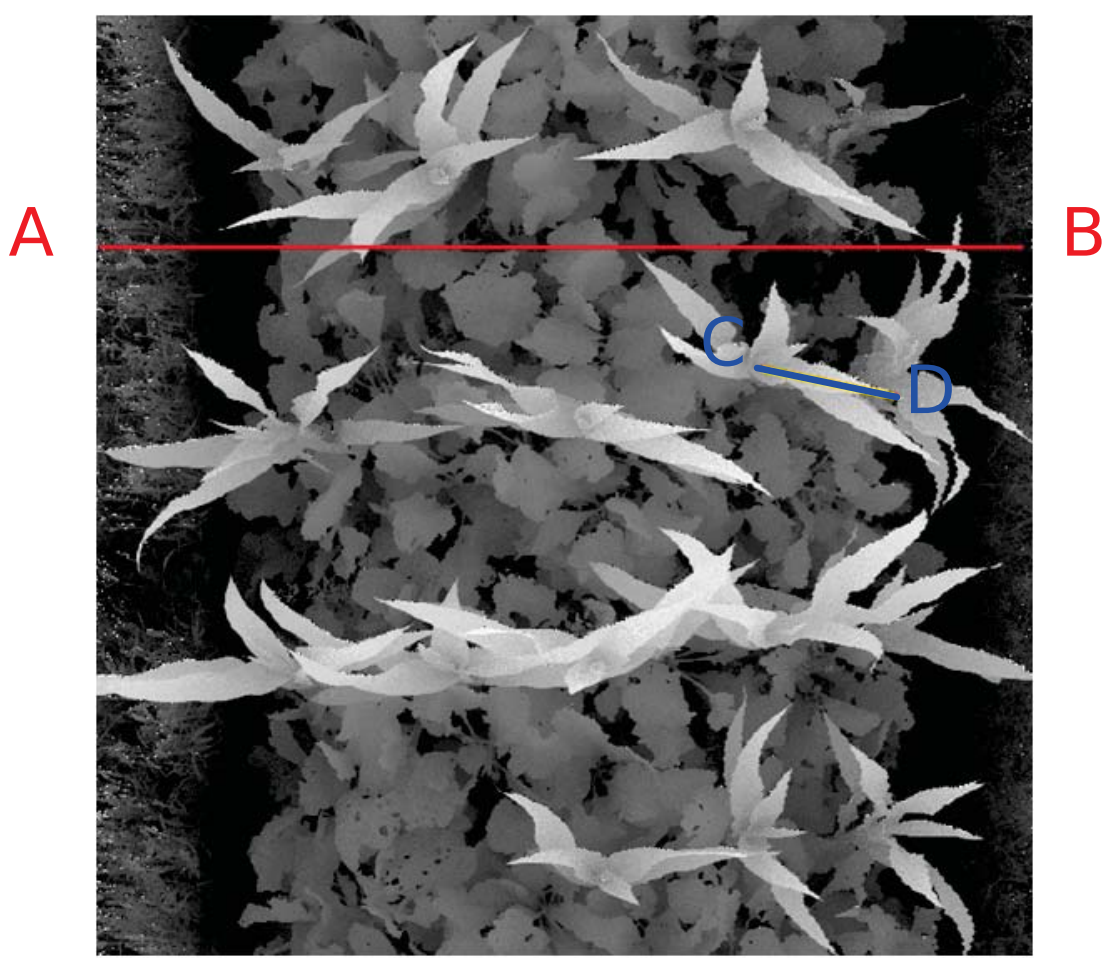

b)

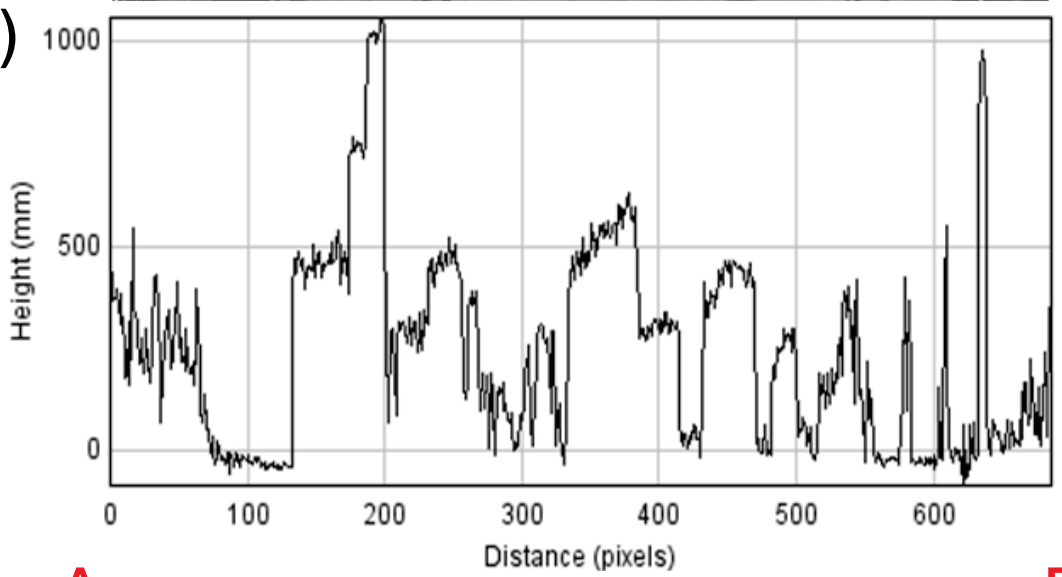

C)
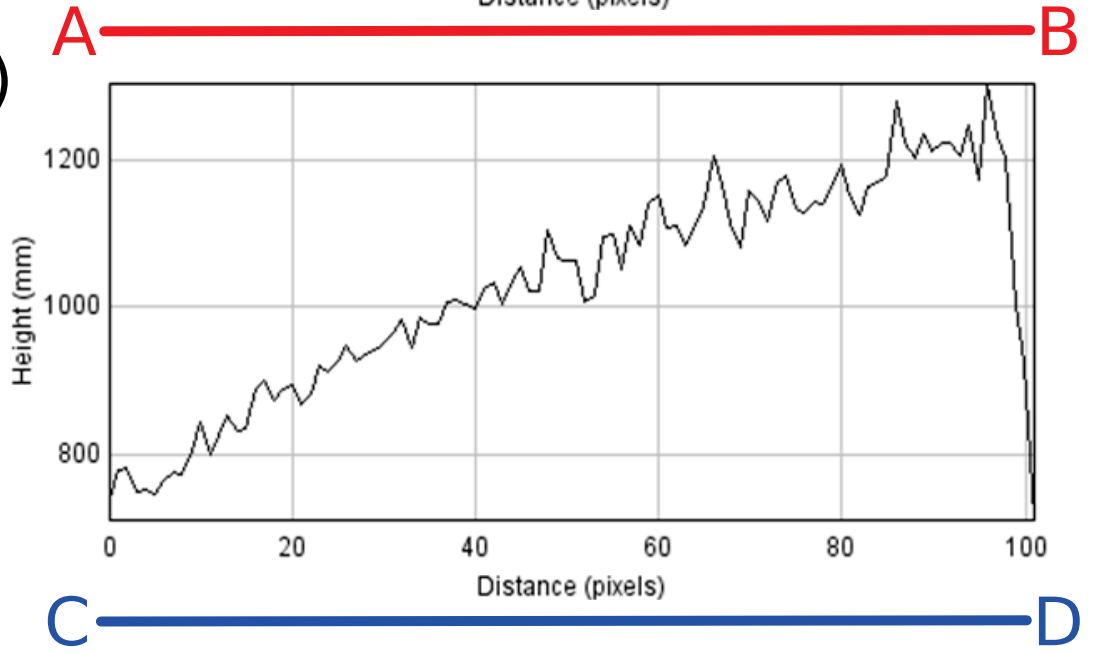
Figure 4. Profile of the LiDAR elevation. The yellow line in the graph represents the profile of the single-pixel width transect across the plots, denoted in yellow in the image; while the orange line in the graph represents the average height of all the pixels between the two orange lines in the image.
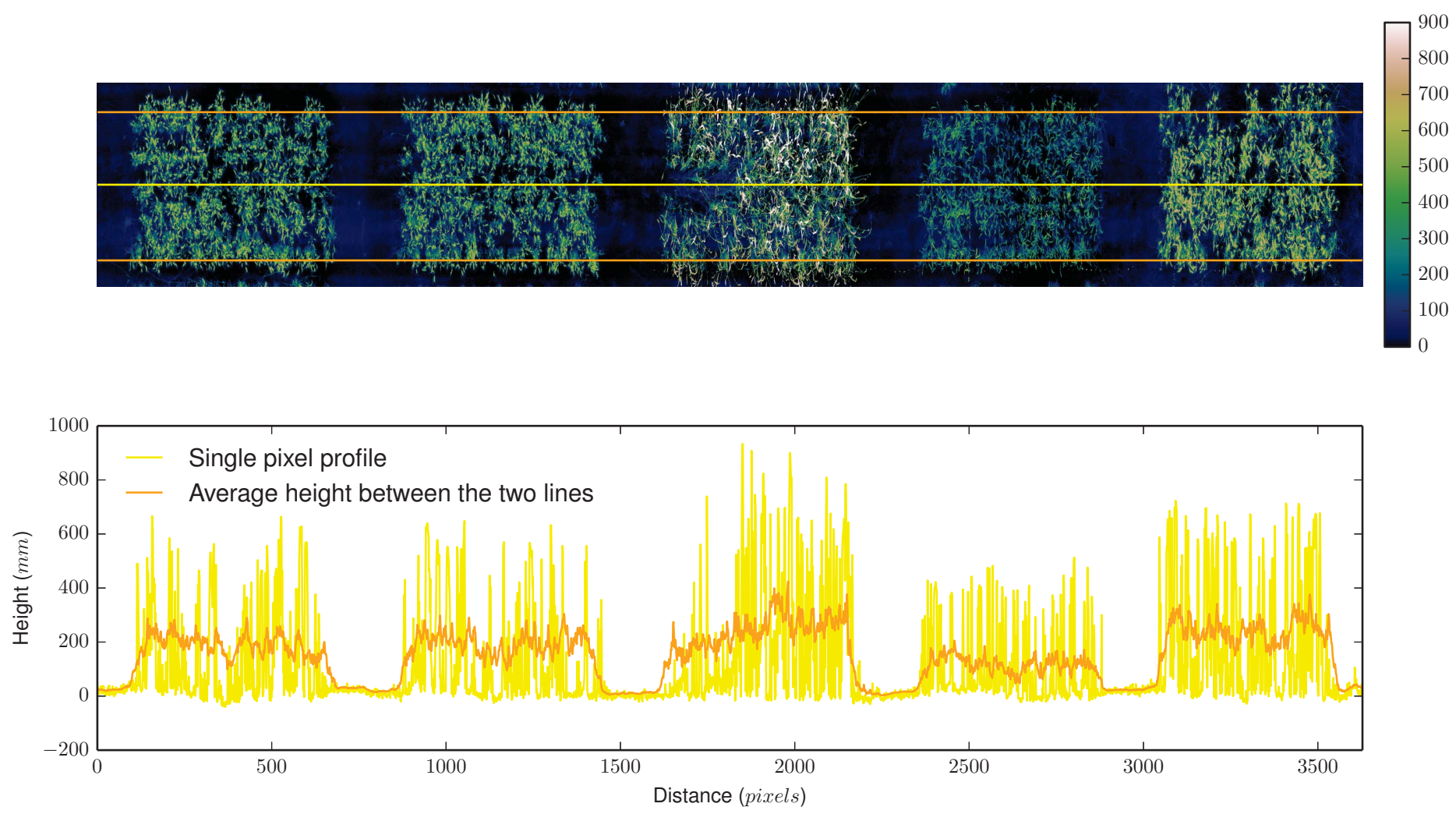
Figure 5. Comparison of canopy height measured manually on wheat using the traditional ruler method and the height estimated with the LiDAR. The resulting relationship shows $R^{2}=86$ and $R M S E=78.93 \mathrm{~mm}$.

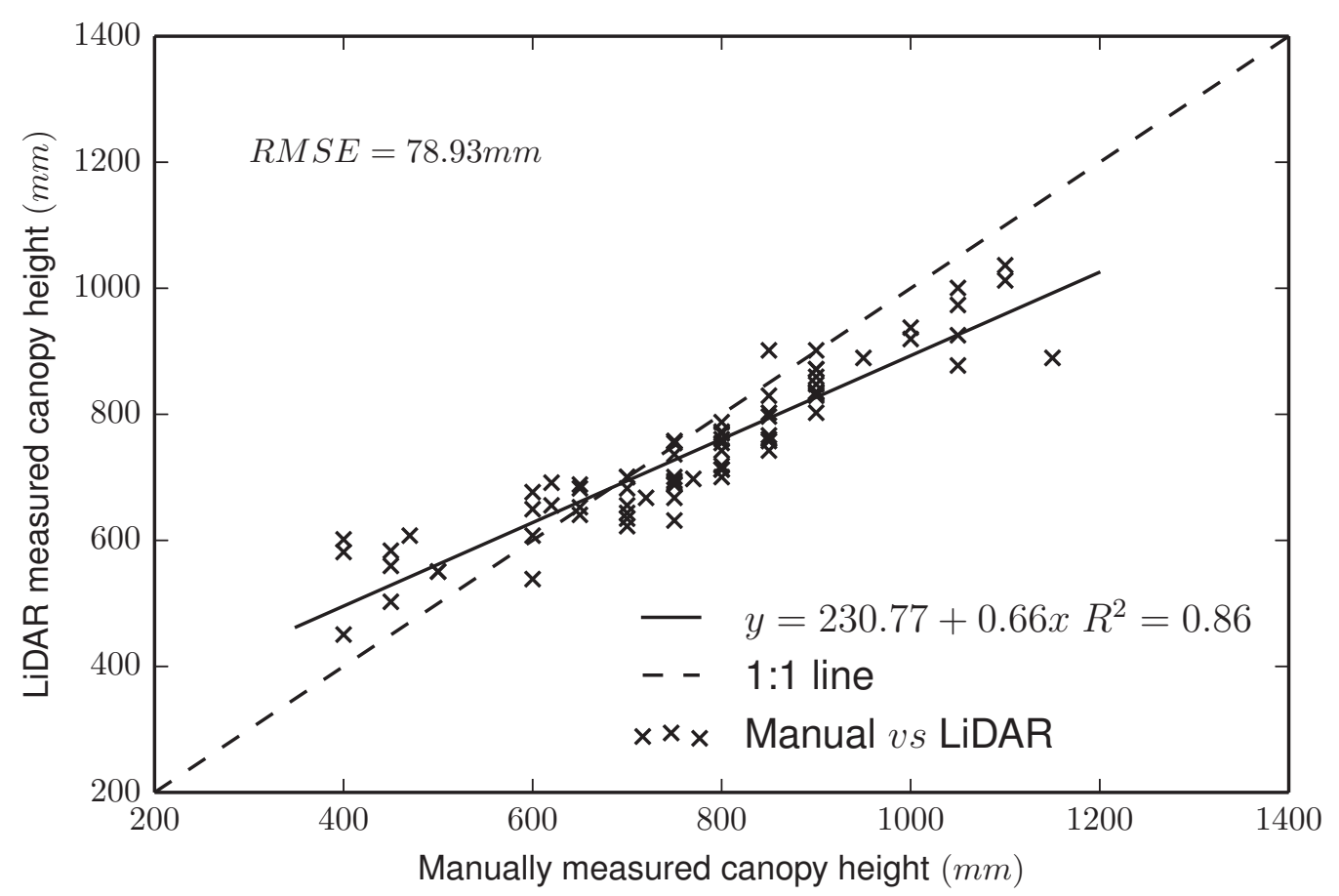


Figure 6. An example of the application of LiDAR for counting spikes in wheat. The LiDAR elevation image (a) can be segmented into an image showing only the top fraction of the image, which clearly shows the spikes (b). A simple particle count algorithm can be used to count the number of elements per area.

a)

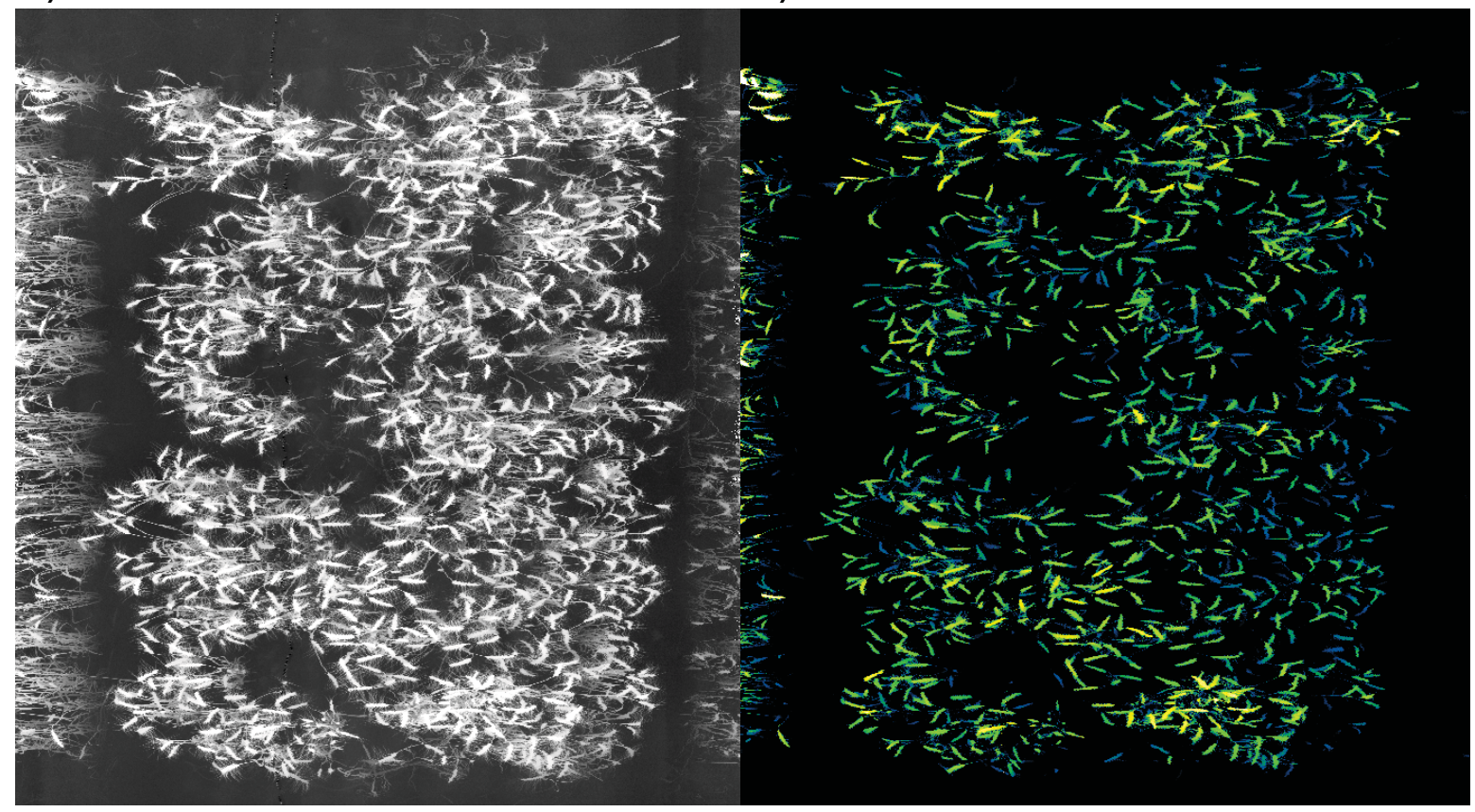

There are different approaches for processing and interpreting LiDAR data. The examples shown above (Figures 3-6) deal with the information in the form of raster images. The returns of the LiDAR are converted into distances and angles and then converted into an image. This has the advantage of using standard image processing software for analysing the data. The alternative to this method is the generation of point clouds with $x, y, z$ coordinates associated with attributes, such as the intensity of the return. Each return of the LiDAR is converted into a 3D point (Figure 7a). This requires specific software to deal with the large number of point clouds generated from each LiDAR run. One way to deal with the point cloud using standard image analysis software is to convert the point cloud into a voxel image. A voxel (volume element) is the 3D equivalent to a pixel. Voxels are calculated by creating a grid of cubes that overlap with the point cloud. For each of these cubes or voxels, it is possible to calculate attributes, such as the number of returns, into the voxel or average intensity. Then, the resulting 3D array of voxels can be exported as a multi-layered image that can be processed using most image analysis software. The use of voxels is also amenable to the estimation of crop bio-volume and biomass or as the input format for radiative transfer models [112,113]. 
Figure 7. Point cloud calculated from the LiDAR. (a) Perspective view of the point cloud; top view (b) and side view (c) of the voxels calculated from the point cloud.

a)

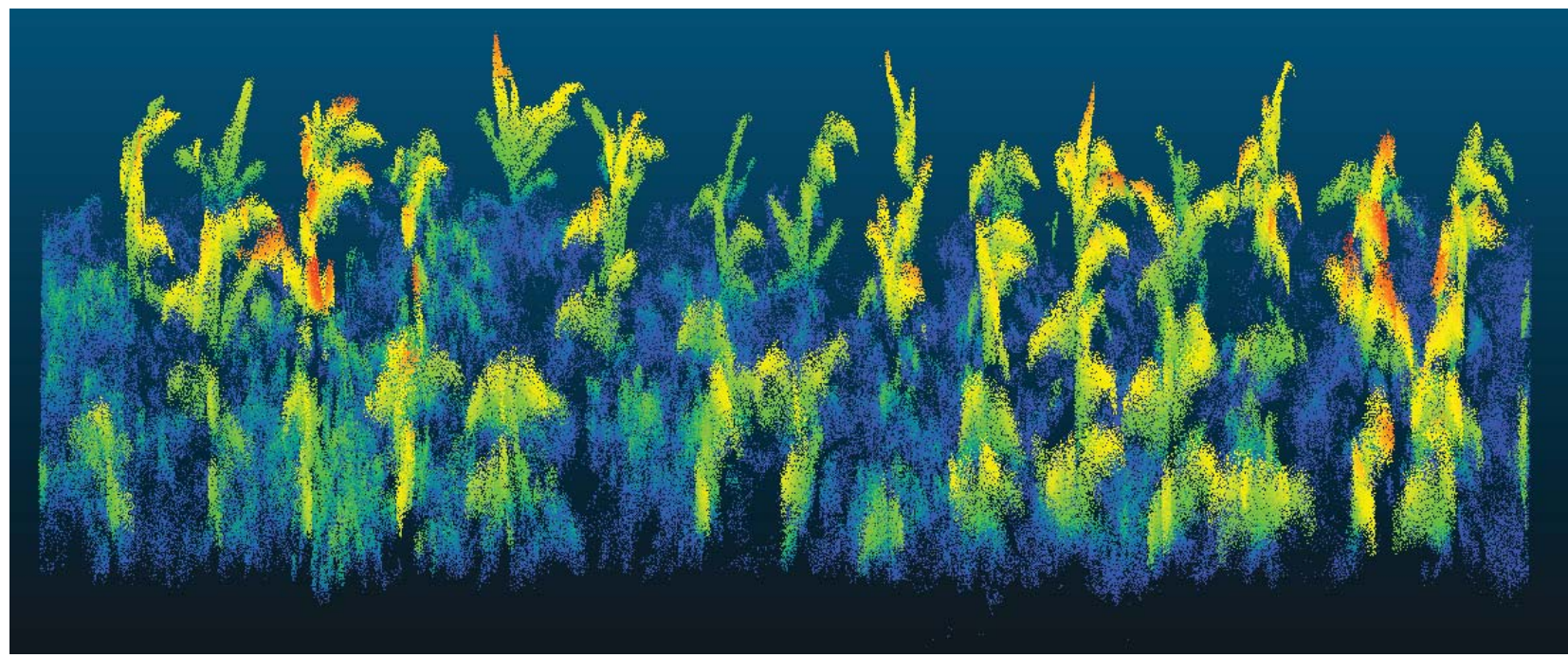

b)

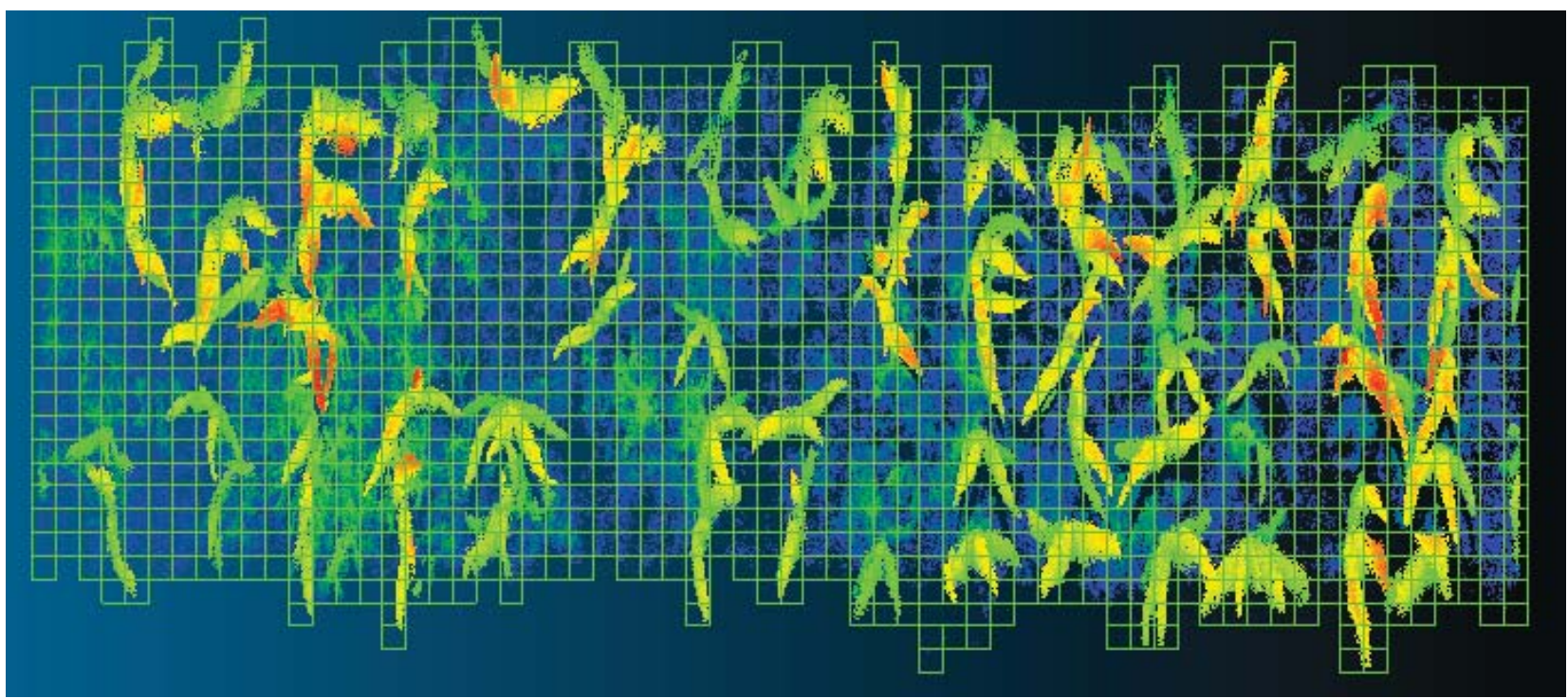

C)

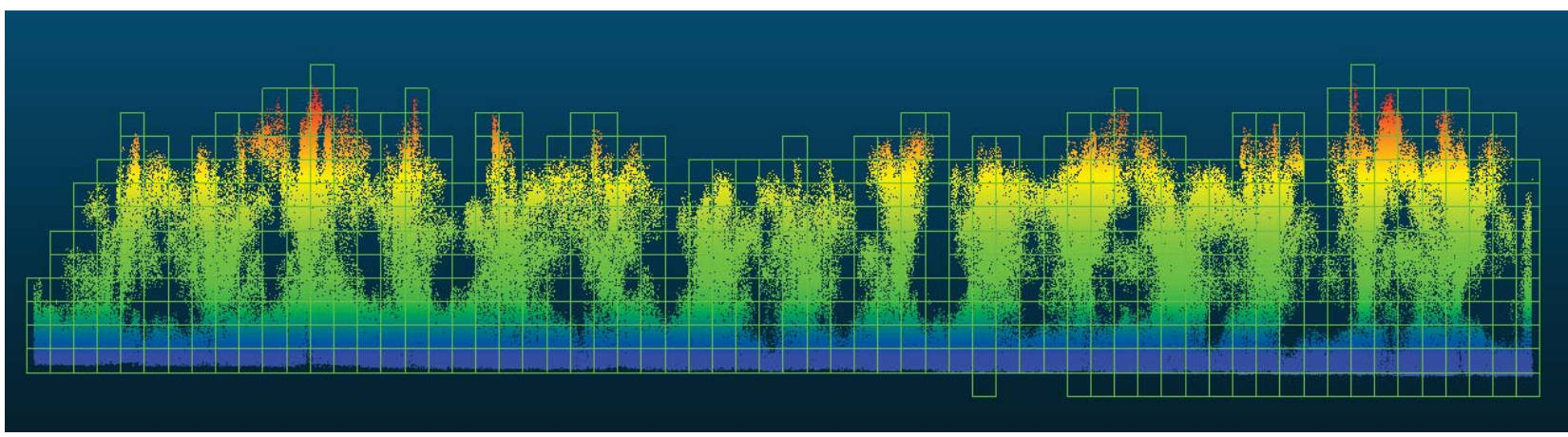




\subsubsection{RGB Camera Subsystem}

Using two RGB cameras (Flea2 5MP, Point Grey Research Inc., Richmond, Canada), we estimated the leaf area and volume of a Japanese millet (Echinochloa esculenta) and forage Brassica (Brassica napus) crop sown at three densities in $10-\mathrm{m}^{2}$ plots ( 0.5 times normal density, 1 times normal density and 1.5 times normal density). Volume and/or surface area are assumed here to be proxies for standing biomass. The pairs of acquired RGB images were first corrected for radial distortion ("undistorted") to account for imperfection in the manufacturing process of the lenses [114,115] and rectified to account for the non-co-planarity of the optical system [116] before being matched using a stereo algorithm [117]. This generated a disparity map. Using a pin-hole model of the camera [118], each point of the disparity map was registered to a real-world coordinate system. The disparity map was then used to produce an elevation map of the scene. Bio-volume was then computed by integrating the surface below the leaves and the soil surface along the depth coordinate. Figure 8 a shows an example result from 3D surface reconstruction using the RGB stereo system on the Phenomobile platform. Sampling of standing biomass was performed by cutting at ground level the total above-ground biomass contained in a $0.5-\mathrm{m}^{2}$ quadrat. These destructive samples were dehydrated for three days at $110{ }^{\circ} \mathrm{C}$ before being weighed to the nearest gram. The relationship between standing biomass and calculated bio-volume (Figure 8b) was species specific, whereby the offset differed by a factor of two, while the slopes were similar. While it is possible to calculate bio-volume and many of the canopy structure parameters listed in Table 3 with pairs of acquired RGB images, the advantages of the LiDAR compared to the RGB camera, described earlier (Section 4.1.1), are worth considering when selecting sensor technology for phenotyping canopy structure traits.

Figure 8. (a) Surface reconstruction of a small region of Figure 3 (due to the rectification steps, parts of the plants are missing in the rectified images); (b) volume estimation (in $\mathrm{cm}^{3}$ ) $v s$. destructive sampling (in grams); variation reflects the different sowing densities of $0.5,1$ and 1.5 times normal sowing density.

a)

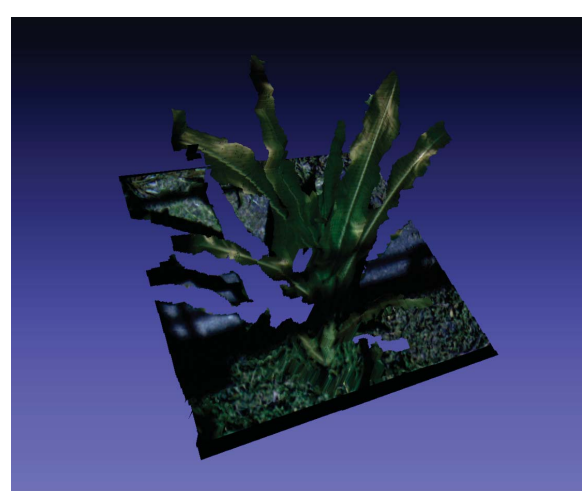

b)

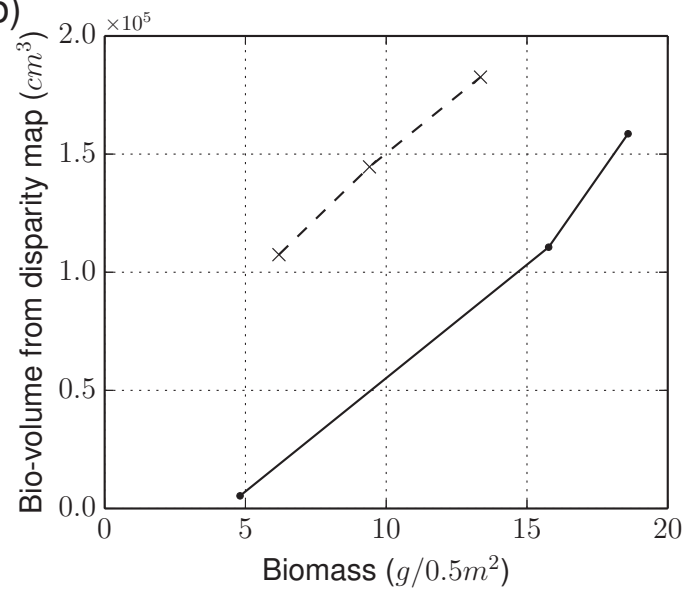

$\bullet$ Brassica napus $\star *$ Echinochloa esculenta

\subsubsection{Hyperspectral Subsystem}

There are two hyperspectral sensors on the Phenomobile. A full-range spectroradiometer (Fieldspec 3, ASD Inc., Boulder, CO, USA) and a Vis-NIR hyperspectral line scanner camera 
(Micro-Hyperspec, Headwall Photonics Inc., Fitchburg, MA, USA). The full-range spectroradiometer is programmed to acquire continuous spectra at approximately $1 \mathrm{~Hz}$ that are geo-referenced using the RTK GPS on the Phenomobile. A foreoptic of $18^{\circ}$ FOV is installed on the optic fibre, providing an $80 \mathrm{~mm}$ diameter spot over the plot at a boom height of $2.5 \mathrm{~m}$. The spectra are acquired in radiance and then converted into reflectance using either a second full-range spectroradiometer fitted with the cosine corrector and making continuous measurements of the incoming irradiance or using a radiative transfer model to model irradiance from aerosol optical depth obtained from the NASA Aeronet station in Canberra. Since each spectrum is geo-referenced, it is possible to extract the collection of spectra corresponding to each plot. Then, a number of vegetation indices are calculated from the average plot reflectances of the different spectral bands.

The hyperspectral camera can record images at a maximum frame rate of $90 \mathrm{~Hz}$. The resolution of the camera in the spatial axis is 1004 pixels, which, with the current foreoptics of $25^{\circ} \mathrm{FOV}$ and a $2.5-\mathrm{m}$ boom height, results in a 1.1-mm spatial resolution. However, the spatial resolution in the direction of travel is determined by the speed of the Phenomobile and the frame rate of the camera. At the maximum frame rate $(90 \mathrm{~Hz})$ and a travel speed of $1 \mathrm{~m} / \mathrm{s}$, the spatial resolution in the direction of travel is approximately $11 \mathrm{~mm}$. Therefore, in order to get square pixels, it is required to travel at a lower speed or apply spatial binning in order to reduce the spatial resolution on the axis perpendicular to the travel. Each scanned line is time-tagged with GPS time, which is used for geo-referencing each line based on the information from the RTK-GPS and wheel encoders on the Phenomobile. The camera is calibrated into radiance using a uniform light source based on an integrating sphere (USS-2000S, Labsphere, North Sutton, NH, USA). Then, the conversion into reflectance is similar to the one applied to the radiance measurements from the full range spectroradiometer. The resulting image has 340 spectral bands with a spectral resolution of approximately $2 \mathrm{~nm}$. The example in Figure 9 shows a wheat experiment comprising two plots with higher and lower plant density; Plot_A (denoted in yellow, lower plant density) and Plot_B (denoted in red, higher plant density). The true color image is an RGB composite rendered using the visible bands. From the hyperspectral image, it is possible to calculate a range of different vegetation indices. For example, the NDVI and PRI are presented in Figure 9, whereby the average NDVI and PRI for the lower plant density plot, Plot_A (0.58 and -0.047 , respectively), is less than that for the higher plant density plot, Plot_B (0.68 and -0.027 , respectively).

Given the resolution of the hyperspectral system, it is possible to extract the reflectance from individual plants and, thereby, discriminate between the individual plant organs, such as spikes and flag leaves. See, for example, Figure 9, where Plant_1, denoted in blue, is the average reflectance of a region of interest manually drawn over a single plant. In the case of incomplete canopies, where part of the soil background is presented in the image, a simple NDVI-based mask can be used to filter out pixels with low NDVI representing soil or shadows; therefore, only pixels with vegetation would be used in the analysis. 
Figure 9. Hyperspectral image of wheat with the camera mounted on Phenomobile. From top to bottom: a true color composite showing the selection of two plots differing for plant density (Plot_A in yellow, lower plant density, and Plot_B in red, higher plant density) and a single plant (Plant_1 in a blue circle); an NDVI image from the same hyperspectral image; a PRI image; a close-up look at Plot_A; plots of spectral radiance of Plot_A, Plot_B and Plant_1.
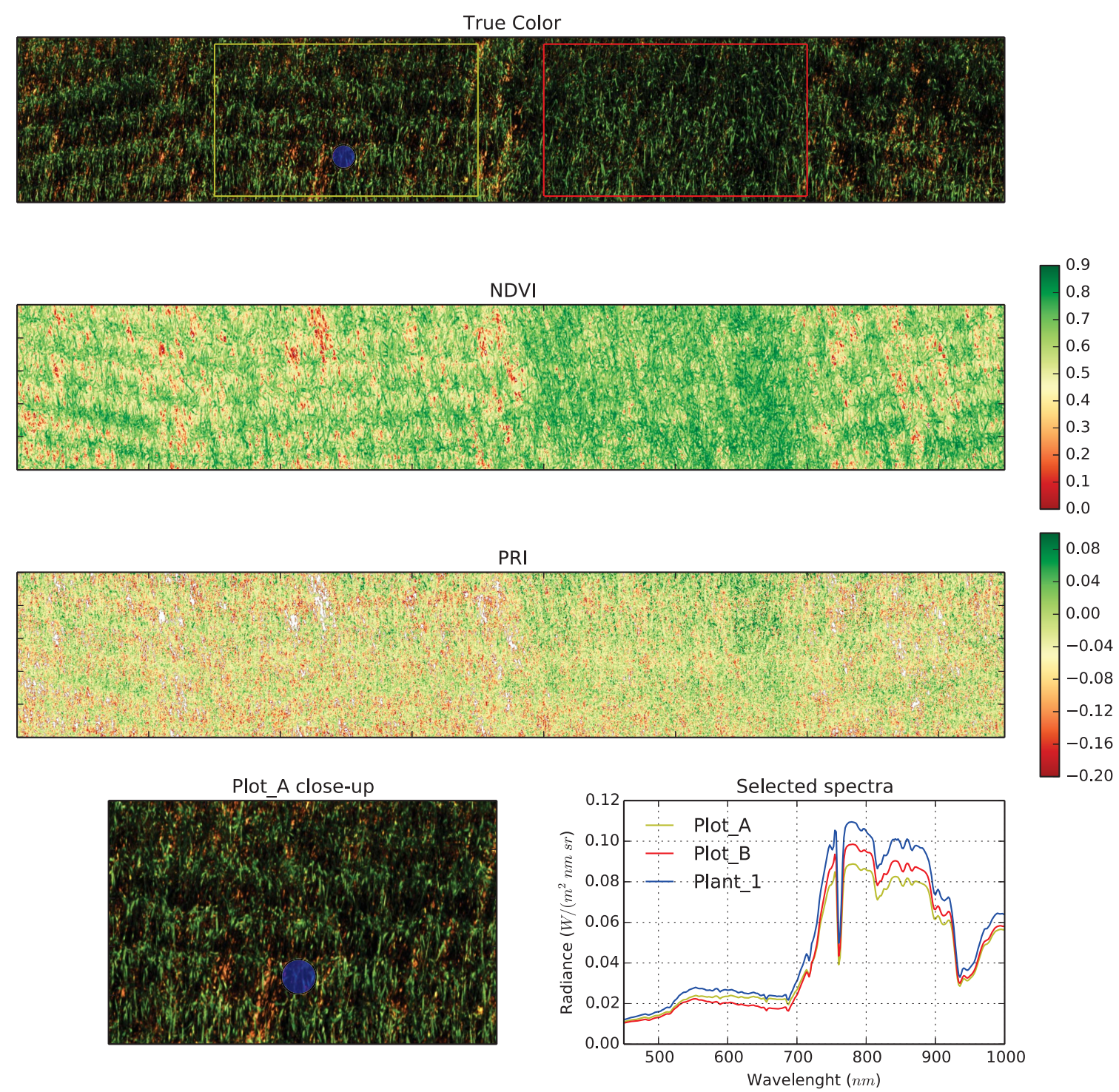

For the application of proximal hyperspectral technology in field phenotyping to derive the biochemistry traits listed in Table 3, high spatial resolution is critical for extracting the spectral information from pure vegetation or even individual organs within a plant. In hyperspectral remote sensing, scaling up from the leaf level to the canopy scale is one of the biggest challenges. Spectral measurements and established vegetation indices known to work well for determining pigment concentration or photosynthetic functioning at the leaf scale do not necessarily maintain the same relationship at the canopy scale. In the application of phenotyping across genotypically diverse populations, where one may expect a broad range of canopy architectures, scaling from leaf to canopy becomes even more challenging. 
The ability to extract the pixels from the hyperspectral image that represents the reflectance of a well-illuminated leaf is only possible by using an imaging sensor with high spatial resolution. Moreover, the combination of hyperspectral and the structural information obtained from the LiDAR will enable the fusion of both datasets and permit the filtering of the spectral pixels on plant material to those with unique sensor/sun geometry. This filtering technique can remove artifacts caused by differences in canopy architecture and has been explored at the airborne level [119] over natural vegetation; therefore, the same techniques that are applied with sub-metre imagery could be applied to sub-centimetre datasets and single plants in field phenotyping.

\subsubsection{Thermal Infrared Camera}

The images captured by the thermal infrared camera (SC645, FLIR Systems Australia Pty Ltd, Notting Hill, VIC, Australia) mounted on the Phenomobile contain sufficient resolution to identify individual leaves in a wheat canopy (Figure 10). This level of resolution presents opportunities to threshold soil from plant material and to overcome the complexities that arise from the influence of the background soil temperature. Such complexities are increased when single pixel thermal infrared sensors are used to measure the temperature of canopies with incomplete ground cover and row crops. Other opportunities exist for identifying individual plant organs within the canopy to estimate transpiring and non-transpiring plant material, as well as their relative contribution to the overall canopy transpiration at a particular time during the growing season. Such an analysis could be used to evaluate traits contributing to the duration of the grain-filling period in cereals, sometimes referred to as "stay green", and to estimate the transpiration of reproductive organs. However, to compare consecutive temperature measurements of a large number of experimental plots, one must account for the influence of the changing environment with time on the measured temperature (discussed previously in Section 3.1.5).

Figure 10. A single thermal image obtained with Phenomobile over wheat. The image shows the contrast between the temperatures of the soil and the individual plants. In this example, the soil was recently irrigated, and most of the soil is cooler than the actual canopy.

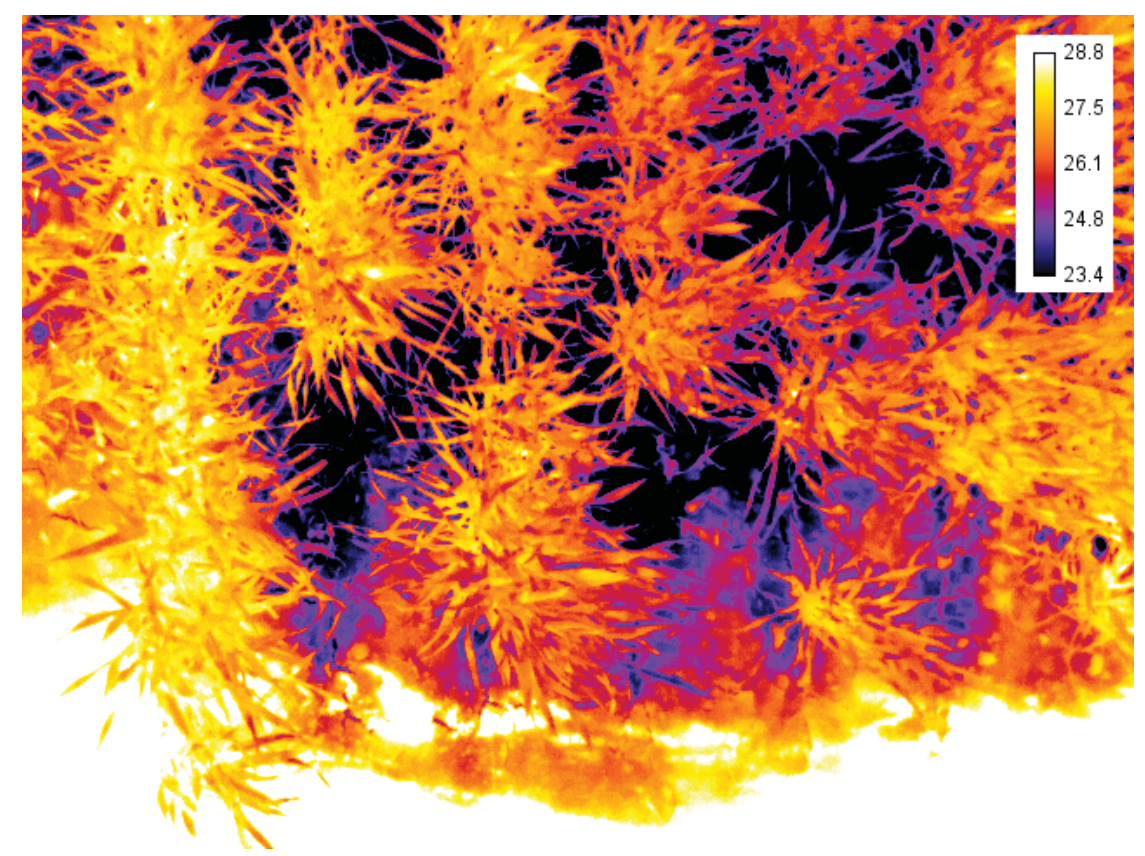




\section{Conclusions}

Obtaining useful information from proximal remote sensing buggies for use by breeders and physiologists is a considerable challenge that has been identified by others [11]. For low-throughput applications, like intensive physiology investigations, less automation and greater human intervention in the data processing and analysis is acceptable. However, for commercial-scale breeding and pre-breeding applications, mature data acquisition and automated data processing systems are required to keep pace with the demand imposed by the large number of genotypes deployed across sites and environment types. The latter application can often require expert level skills and capabilities in the software engineering and computer science domains, necessitating genuine multidisciplinary collaborations to achieve substantive outcomes. Multidisciplinary teams are required to overcome challenges with: hardware and software integration; customization of data processing and analysis; efficient georeferencing of the data to an experimental field plan and timely delivery of the data, preferably through secure web-based portals, to inform decision-making. Today, the crop science community can leverage the unprecedented technology advances made in computer science, image analysis, proximal remote sensing and robotics.

\section{Acknowledgments}

This work was funded through the National Collaborative Research Infrastructure Strategy (Australian Plant Phenomics Facility) and the Grains Research and Development Corporation (CSP00148). Allan Rattey supplied the manual measurements of crop canopy height shown in Figure 5. Xiao Tan implemented the stereo reconstruction algorithm for Figure 8.

\section{Author Contributions}

David Deery, Jose Jimenez-Berni, Xavier Sirault and Robert Furbank conceived of, designed and undertook the research presented in the case study. David Deery, Jose Jimenez-Berni and Hamlyn Jones contributed to the overall conception and writing of the article with input and advice from Xavier Sirault and Robert Furbank.

\section{Conflicts of Interest}

The authors declare no conflicts of interest.

\section{References}

1. Bruinsma, J. The resource outlook to 2050. By how much do land, water use and crop yields need to increase by 2050? In Proceedings of the FAO Expert Meeting on How to Feed the World in 2050, 24-26 June 2009; FAO: Rome, Italy, 2009.

2. Royal Society of London. Reaping the Benefits: Science and the Sustainable Intensification of Global Agriculture; Technical Report; Royal Society: London, UK, 2009.

3. Tilman, D.; Balzer, C.; Hill, J.; Befort, B.L. Global food demand and the sustainable intensification of agriculture. Proc. Natl. Acad. Sci. USA 2011, 108, 20260-20264. 
4. Hall, A.; Wilson, M.A. Object-based analysis of grapevine canopy relationships with winegrape composition and yield in two contrasting vineyards using multitemporal high spatial resolution optical remote sensing. Int. J. Remote Sens. 2013, 34, 1772-1797.

5. Ingvarsson, P.K.; Street, N.R. Association genetics of complex traits in plants. New Phytol. 2011, 189, 909-922.

6. Rebetzke, G.; van Herwaarden, A.; Biddulph, B.; Moeller, C.; Richards, R.; Rattey, A.; Chenu, K. Field Experiments in Crop Physiology, 2013. Available online: http://prometheuswiki.publish.csiro.au/ tiki-pagehistory.php?page=Field $\% 20 \mathrm{E} \%$ xperiments $\% 20$ in $\% 20 \mathrm{Crop} \% 20 \mathrm{Physiology} \&$ preview $=41$ (accessed on 22 January 2014).

7. Pask, A.; Pietragalla, J.; Mullan, D.; Reynolds, M. Physiological Breeding II: A Field Guide to Wheat Phenotyping; Technical Report; CIMMYT: Mexico, DF, Mexico, 2012.

8. Tuberosa, R. Phenotyping for drought tolerance of crops in the genomics era. Front. Physiol. 2012, 3, doi:10.3389/fphys.2012.00347.

9. Cobb, J.N.; DeClerck, G.; Greenberg, A.; Clark, R.; McCouch, S. Next-generation phenotyping: Requirements and strategies for enhancing our understanding of genotype-phenotype relationships and its relevance to crop improvement. Theor. Appl. Genet. 2013, 126, 867-887.

10. Araus, J.L.; Cairns, J.E. Field high-throughput phenotyping: The new crop breeding frontier. Trends Plant Sci. 2014, 19, 52-61.

11. White, J.W.; Andrade-Sanchez, P.; Gore, M.A.; Bronson, K.F.; Coffelt, T.A.; Conley, M.M.; Feldmann, K.A.; French, A.N.; Heun, J.T.; Hunsaker, D.J.; et al. Field-based phenomics for plant genetics research. Field Crops Res. 2012, 133, 101-112.

12. Cabrera-Bosquet, L.; Crossa, J.; von Zitzewitz, J.; Serret, M.D.; Araus, J.L. High-throughput phenotyping and genomic selection: The frontiers of crop breeding converge. J. Integr. Plant Biol. 2012, 54, 312-320.

13. Fussell, J.; Rundquist, D. On defining remote sensing. Photogramm. Eng. Remote Sens. 1986, $52,1507-1511$.

14. Fiorani, F.; Schurr, U. Future scenarios for plant phenotyping. Annu. Rev. Plant Biol. 2013, 64, 267-291.

15. Furbank, R.T.; Tester, M. Phenomics-technologies to relieve the phenotyping bottleneck. Trends Plant Sci. 2011, 16, 635-644.

16. Walter, A.; Studer, B.; Kolliker, R. Advanced phenotyping offers opportunities for improved breeding of forage and turf species. Ann. Bot. 2012, 110, 1271-1279.

17. Rebetzke, G.J.; Fischer, R.T.A.; van Herwaarden, A.F.; Bonnett, D.G.; Chenu, K.; Rattey, A.R.; Fettell, N.A. Plot size matters: Interference from intergenotypic competition in plant phenotyping studies. Funct. Plant Biol. 2013, 41, 107-118.

18. Amani, I.; Fischer, R.A.; Reynolds, M.F.P. Canopy Temperature Depression Association with Yield of Irrigated Spring Wheat Cultivars in a Hot Climate. J. Agron. Crop Sci. 1996, 176, 119-129.

19. Brennan, J.P.; Condon, A.G.; van Ginkel, M.; Reynolds, M.P. An economic assessment of the use of physiological selection for stomatal aperture-related traits in the CIMMYT wheat breeding programme. J. Agric. Sci. 2007, 145, 187-194. 
20. Condon, A.G.; Reynolds, M.P.; Rebetzke, G.J.; van Ginkel, M.; Richards, R.A.; Farquhar, G.D. Using stomatal aperture-related traits to select for high yield potential in bread wheat. Wheat Prod. Stressed Environ. 2007, 12, 617-624.

21. Jones, H.G.; Serraj, R.; Loveys, B.R.; Xiong, L.; Wheaton, A.; Price, A.H. Thermal infrared imaging of crop canopies for the remote diagnosis and quantification of plant responses to water stress in the field. Funct. Plant Biol. 2009, 36, 978-989.

22. Prashar, A.; Yildiz, J.; McNicol, J.W.; Bryan, G.J.; Jones, H.G. Infra-red thermography for high throughput field phenotyping in Solanum tuberosum. PLoS One 2013, 8, e65816.

23. Anderson, K.; Gaston, K.J. Lightweight unmanned aerial vehicles will revolutionize spatial ecology. Front. Ecol. Environ. 2013, 11, 138-146.

24. Chapman, S.C.; Merz, T.; Chan, A.; Jackway, P.; Hrabar, S.; Dreccer, M.F.; Holland, E.; Zheng, B.; Ling, T.J.; Jimenez-Berni, J. Pheno-Copter: A Low-Altitude, Autonomous Remote-Sensing Robotic Helicopter for High-Throughput Field-Based Phenotyping. Agronomy 2014, 4, 279-301.

25. Labbé, S.; Lebourgeois, V.; Virlet, N.; Martínez, S.; Regnard, J.L. Contribution of airborne remote sensing to high- throughput phenotyping of a hybrid apple population in response to soil water constraints. In Proceedings of the 2nd International Plant Phenotyping Symposium, Jülich, Germany, 5-7 September 2011; International Plant Phenomics Network; pp. 185-191.

26. Matese, A.; Primicerio, J.; di Gennaro, F.; Fiorillo, E.; Vaccari, F.P.; Genesio, L. Development and application of an autonomous and flexible unmanned aerial vehicle for precision viticulture. In Acta Horticulturae; Poni, S., Ed.; International Society for Horticultural Science (ISHS): Leuven, Belgium, 2013; pp. 63-69.

27. Perry, E.M.; Brand, J.; Kant, S.; Fitzgerald, G.J. Field-based rapid phenotyping with Unmanned Aerial Vehicles (UAV). In Proceedings of 16th Agronomy Conference 2012, Armidale, NSW, Australia, 14-18 October 2012; Australian Society of Agronomy: Armidale, NSW, Australia, 2012.

28. Zarco-Tejada, P.; Berni, J.; Suárez, L.; Sepulcre-Cantó, G.; Morales, F.; Miller, J. Imaging chlorophyll fluorescence with an airborne narrow-band multispectral camera for vegetation stress detection. Remote Sens. Environ. 2009, 113, 1262-1275.

29. Zarco-Tejada, P.; González-Dugo, V.; Berni, J. Fluorescence, temperature and narrow-band indices acquired from a UAV platform for water stress detection using a micro-hyperspectral imager and a thermal camera. Remote Sens. Environ. 2012, 117, 322-337.

30. Zarco-Tejada, P.; Guillén-Climent, M.; Hernández-Clemente, R.; Catalina, A.; González, M.; Martín, P. Estimating leaf carotenoid content in vineyards using high resolution hyperspectral imagery acquired from an unmanned aerial vehicle (UAV). Agric. For. Meteorol. 2013, 171-172, 281-294.

31. LemnaTec GmbH. Scanalyzer Field—LemnaTec. Available online: http://www.lemnatec.com/ product/scanalyzer-field (accessed on 28 January 2014).

32. ETH Zurich. ETH-Crop Science-Field Phenotyping Platform (FIP). Available online: http://www.kp.ethz.ch/infrastructure/FIP (accessed on 28 January 2014). 
33. Romano, G.; Zia, S.; Spreer, W.; Sanchez, C.; Cairns, J.; Araus, J.L.; Müller, J. Use of thermography for high throughput phenotyping of tropical maize adaptation in water stress. Comput. Electron. Agric. 2011, 79, 67-74.

34. White, J.W.; Conley, M.M. A Flexible, Low-Cost Cart for Proximal Sensing. Crop Sci. 2013, 53, 1646-1649.

35. Ruckelshausen, A.; Biber, P.; Doma, M.; Gremmes, H.; Klose, R.; Linz, A.; Rahne, R.; Resch, R.; Thiel, M.; Trautz, D.; et al. BoniRob: An autonomous field robot platform for individual plant phenotyping. In Proceedings of the Joint International Agricultural Conference (2009), Wageningen, Netherlands, 6-8 July 2009; van Henten, E.J., Goense, D., Lokhorst, C., Eds.; Wageningen Agricultural Publishers: Wageningen, Netherlands, 2009; pp. 841-847.

36. Jensen, K.H.; Nielsen, S.H.; Jørgensen, R.N.; Bøgild, A.; Jacobsen, N.J.; Jørgensen, O.J.; Jaeger-Hansen, C.H. A Low Cost, Modular Robotics Tool Carrier For Precision Agriculture Research. In Proceedings of the 11th International Conference on Precision Agriculture, Indianapolis, IN, USA, 15-18 July 2012; International Society of Precision Agriculture.

37. Andrade-Sanchez, P.; Gore, M.A.F.; Heun, J.T.; Thorp, K.R.; Carmo-Silva, A.E.; French, A.N.; Salvucci, M.E.; White, J.W. Development and evaluation of a field-based high-throughput phenotyping platform. Funct. Plant Biol. 2014, 41, 68-79.

38. Busemeyer, L.; Klose, R.; Linz, A.; Thiel, M.; Wunder, E.; Ruckelshausen, A. Agro-sensor systems for outdoor plant phenotyping in low and high density crop field plots. In Proceedings of the Landtechnik 2010-Partnerschaften für neue Innovationspotentiale, Düsseldorf, Germany, 27-28 October 2010; pp. 213-218.

39. Busemeyer, L.; Mentrup, D.; Möller, K.; Wunder, E.; Alheit, K.; Hahn, V.; Maurer, H.P.; Reif, J.C.; Würschum, T.; Müller, J.; et al. BreedVision-A Multi-Sensor Platform for Non-Destructive Field-Based Phenotyping in Plant Breeding. Sensors 2013, 13, 2830-2847.

40. Comar, A.; Burger, P.; de Solan, B.; Baret, F.; Daumard, F.; Hanocq, J.F. A semi-automatic system for high throughput phenotyping wheat cultivars in-field conditions: Description and first results. Funct. Plant Biol. 2012, 39, 914-924.

41. Casadesús, J.; Kaya, Y.; Bort, J.; Nachit, M.M.; Araus, J.L.; Amor, S.; Ferrazzano, G.; Maalouf, F.; Maccaferri, M.; Martos, V.; et al. Using vegetation indices derived from conventional digital cameras as selection criteria for wheat breeding in water-limited environments. Ann. Appl. Biol. 2007, 150, 227-236.

42. Jones, H.G.; Vaughan, R.A. Remote Sensing of Vegetation: Principles, Techniques, and Applications; Oxford University Press: Oxford, UK, 2010; p. 369.

43. Lee, K.J.; Lee, B.W. Estimation of rice growth and nitrogen nutrition status using color digital camera image analysis. Eur. J. Agron. 2013, 48, 57-65.

44. Liu, J.; Pattey, E. Retrieval of leaf area index from top-of-canopy digital photography over agricultural crops. Agric. For. Meteorol. 2010, 150, 1485-1490.

45. Liu, L.; Peng, D.; Hu, Y.; Jiao, Q. A novel in situ FPAR measurement method for low canopy vegetation based on a digital camera and reference panel. Remote Sens. 2013, 5, 274-281.

46. Baret, F.; de Solan, B.; Lopez-Lozano, R.; Ma, K.; Weiss, M. GAI estimates of row crops from downward looking digital photos taken perpendicular to rows at $57.5^{\circ}$ zenith angle: 
Theoretical considerations based on 3D architecture models and application to wheat crops. Agric. For. Meteorol. 2010, 150, 1393-1401.

47. Foucher, P.; Revollon, P.; Vigouroux, B.; Chassériaux, G. Morphological Image Analysis for the Detection of Water Stress in Potted Forsythia. Biosyst. Eng. 2004, 89, 131-138.

48. Paproki, A.; Sirault, X.R.R.; Berry, S.; Furbank, R.T.; Fripp, J. A novel mesh processing based technique for 3D plant analysis. BMC Plant Biol. 2012, 12, doi:10.1186/1471-2229-12-63.

49. Wang, H.; Zhang, W.; Zhou, G.; Yan, G.; Clinton, N. Image-based 3D corn reconstruction for retrieval of geometrical structural parameters. Int. J. Remote Sens. 2009, 30, 5505-5513.

50. Huang, C.; Yang, W.; Duan, L.; Jiang, N.; Chen, G.; Xiong, L.; Liu, Q. Rice panicle length measuring system based on dual-camera imaging. Comput. Electron. Agric. 2013, 98, 158-165.

51. Eitel, J.U.H.; Vierling, L.A.; Long, D.S.; Hunt, E.R. Early season remote sensing of wheat nitrogen status using a green scanning laser. Agric. For. Meteorol. 2011, 151, 1338-1345.

52. Llorens, J.; Gil, E.; Llop, J.; Escolà, A. Ultrasonic and LIDAR sensors for electronic canopy characterization in vineyards: Advances to improve pesticide application methods. Sensors 2011, 11, 2177-2194.

53. Sanz, R.; Rosell, J.; Llorens, J.; Gil, E.; Planas, S. Relationship between tree row LIDAR-volume and leaf area density for fruit orchards and vineyards obtained with a LIDAR 3D Dynamic Measurement System. Agric. For. Meteorol. 2013, 171-172, 153-162.

54. Gebbers, R.; Ehlert, D.; Adamek, R. Rapid Mapping of the Leaf Area Index in Agricultural Crops. Agron. J. 2011, 103, 1532-1541.

55. Hosoi, F.; Omasa, K. Estimating vertical plant area density profile and growth parameters of a wheat canopy at different growth stages using three-dimensional portable lidar imaging. ISPRS J. Photogramm. Remote Sens. 2009, 64, 151-158.

56. Chéné, Y.; Rousseau, D.; Lucidarme, P.; Bertheloot, J.; Caffier, V.V.; Morel, P.; Belin, E.; Chapeau-Blondeau, F.F.; Chene, Y.; Belin, E. On the use of depth camera for 3D phenotyping of entire plants. Comput. Electron. Agric. 2012, 82, 122-127.

57. Klose, R.; Penlington, J.; Ruckelshausen, A. Usability of 3D time-of-flight cameras for automatic plant phenotyping. Bornimer Agrartechnische Berichte 2011, 69, 93-105.

58. Azzari, G.; Goulden, M.L.; Rusu, R.B. Rapid characterization of vegetation structure with a Microsoft Kinect sensor. Sensors 2013, 13, 2384-2398.

59. Aziz, S.A.; Steward, B.L.; Birrell, S.J.; Shrestha, D.S.; Kaspar, T.C. Ultrasonic Sensing for Corn Plant Canopy Characterization. Paper Number 041120. In Proceedings of the 2004 ASAE Annual Meeting, Ottawa, ON, Canada, 1-4 August 2004; American Society of Agricultural and Biological Engineers, St. Joseph, Michigan; pp. 1-11.

60. Makeen, K.; Kerssen, S.; Mentrup, D.; Oeleman, B. Multiple Reflection Ultrasonic Sensor System for Morphological Plant Parameters. Bornimer Agrartech. Berichte 2012, 78, 110-116.

61. Tucker, C.J. Red and photographic infrared linear combinations for monitoring vegetation. Remote Sens. Environ. 1979, 8, 127-150.

62. Hilker, T.; Coops, N.C.; Coggins, S.B.; Wulder, M.A.; Brown, M.; Black, T.A.; Nesic, Z.; Lessard, D. Detection of foliage conditions and disturbance from multi-angular high spectral resolution remote sensing. Remote Sens. Environ. 2009, 113, 421-434. 
63. Zarco-Tejada, P.; Berjón, A.; López-Lozano, R.; Miller, J.; Martín, P.; Cachorro, V.; González, M.; de Frutos, A. Assessing vineyard condition with hyperspectral indices: Leaf and canopy reflectance simulation in a row-structured discontinuous canopy. Remote Sens. Environ. 2005, 99, 271-287.

64. Zarco-Tejada, P.; Catalina, A.; González, M.; Martín, P. Relationships between net photosynthesis and steady-state chlorophyll fluorescence retrieved from airborne hyperspectral imagery. Remote Sens. Environ. 2013, 136, 247-258.

65. Dreccer, M.F.; Barnes, L.R.; Meder, R. Quantitative dynamics of stem water soluble carbohydrates in wheat can be monitored in the field using hyperspectral reflectance. Field Crops Res. 2014, 159, 70-80.

66. Darvishzadeh, R.; Skidmore, A.; Schlerf, M.; Atzberger, C.; Corsi, F.; Cho, M. LAI and chlorophyll estimation for a heterogeneous grassland using hyperspectral measurements. ISPRS J. Photogramm. Remote Sens. 2008, 63, 409-426.

67. Serbin, S.P.; Dillaway, D.N.; Kruger, E.L.; Townsend, P.A. Leaf optical properties reflect variation in photosynthetic metabolism and its sensitivity to temperature. J. Exp. Bot. 2012, 63, 489-502.

68. Zhao, K.; Valle, D.; Popescu, S.; Zhang, X.; Mallick, B. Hyperspectral remote sensing of plant biochemistry using Bayesian model averaging with variable and band selection. Remote Sens. Environ. 2013, 132, 102-119.

69. Römer, C.; Wahabzada, M.; Ballvora, A.; Pinto, F.; Rossini, M.; Panigada, C.; Behmann, J.; Léon, J.; Thurau, C.; Bauckhage, C.; et al. Early drought stress detection in cereals: Simplex volume maximisation for hyperspectral image analysis. Funct. Plant Biol. 2012, 39, 878-890.

70. Seiffert, U.; Bollenbeck, F.; Mock, H.P.; Matros, A. Clustering of crop phenotypes by means of hyperspectral signatures using artificial neural networks. In Proceedings of the 2nd Workshop Hyperspectral Image and Signal Processing: Evolution in Remote Sensing (WHISPERS), Reykjavik, Iceland, 14-16 June 2010; IEEE; pp. 1-4.

71. Féret, J.B.; François, C.; Gitelson, A.; Asner, G.P.; Barry, K.M.; Panigada, C.; Richardson, A.D.; Jacquemoud, S. Optimizing spectral indices and chemometric analysis of leaf chemical properties using radiative transfer modeling. Remote Sens. Environ. 2011, 115, 2742-2750.

72. Garrity, S.R.; Eitel, J.U.H.; Vierling, L.A. Disentangling the relationships between plant pigments and the photochemical reflectance index reveals a new approach for remote estimation of carotenoid content. Remote Sens. Environ. 2011, 115, 628-635.

73. Serrano, L.; González-Flor, C.; Gorchs, G. Assessment of grape yield and composition using the reflectance based Water Index in Mediterranean rainfed vineyards. Remote Sens. Environ. 2012, 118, 249-258.

74. Thiel, M.; Rath, T.; Ruckelshausen, A. Plant moisture measurement in field trials based on NIR spectral imaging: A feasibility study. In Proceedings of the CIGR Workshop on Image Analysis in Agriculture, Budapest, Hungary, 26-27 August 2010; Commission Internationale du Genie Rural: Budapest, Hungary; pp. 16-29.

75. Yi, Q.X.; Bao, A.M.; Wang, Q.; Zhao, J. Estimation of leaf water content in cotton by means of hyperspectral indices. Comput. Electron. Agric. 2013, 90, 144-151. 
76. Gaulton, R.; Danson, F.M.; Ramirez, F.A.; Gunawan, O. The potential of dual-wavelength laser scanning for estimating vegetation moisture content. Remote Sens. Environ. 2013, 132, 32-39.

77. Cheng, T.; Rivard, B.; Sánchez-Azofeifa, A. Spectroscopic determination of leaf water content using continuous wavelet analysis. Remote Sens. Environ. 2011, 115, 659-670.

78. Ullah, S.; Schlerf, M.; Skidmore, A.K.; Hecker, C. Identifying plant species using mid-wave infrared $(2.5-6 \mu \mathrm{m})$ and thermal infrared $(8-14 \mu \mathrm{m})$ emissivity spectra. Remote Sens. Environ. 2012, 118, 95-102.

79. Ullah, S.; Skidmore, A.K.; Groen, T.A.; Schlerf, M. Evaluation of three proposed indices for the retrieval of leaf water content from the mid-wave infrared $(2-6 \mu \mathrm{m})$ spectra. Agric. For. Meteorol. 2013, 171-172, 65-71.

80. De Bei, R.; Cozzolino, D.; Sullivan, W.; Cynkar, W.; Fuentes, S.; Dambergs, R.; Pech, J.; Tyerman, S. Non-destructive measurement of grapevine water potential using near infrared spectroscopy. Aust. J. Grape Wine Res. 2011, 17, 62-71.

81. Elsayed, S.; Mistele, B.; Schmidhalter, U. Can changes in leaf water potential be assessed spectrally? Funct. Plant Biol. 2011, 38, 523-533.

82. Jones, H.G. The use of indirect or proxy markers in plant physiology. Plant, Cell Environ. 2014, $37,1270-1272$.

83. Gamon, J.A.; Peñuelas, J.; Field, C.B. A narrow-waveband spectral index that tracks diurnal changes in photosynthetic efficiency. Remote Sens. Environ. 1992, 41, 35-44.

84. Kolber, Z.; Klimov, D.; Ananyev, G.; Rascher, U.; Berry, J.; Osmond, B. Measuring photosynthetic parameters at a distance: Laser induced fluorescence transient (LIFT) method for remote measurements of photosynthesis in terrestrial vegetation. Photosynth. Res. 2005, 84, 121-129.

85. Perez-Priego, O.; Zarco-Tejada, P.; Miller, J.; Sepulcre-Canto, G.; Fereres, E. Detection of water stress in orchard trees with a high-resolution spectrometer through chlorophyll fluorescence In-Filling of the $\mathrm{O}_{2}$-A band. IEEE Trans. Geosci. Remote Sens. 2005, 43, 2860-2869.

86. Guanter, L.; Alonso, L.; Gómez-Chova, L.; Amorós, J.; Vuila, J.; Moreno, J. A method for detection of solar-induced vegetation fluorescence from MERIS FR data. In Proceedings of the Envisat Symposium 2007, Montreux, Switzerland, 23-27 April 2007; ESA Communication Production Office: Montreux, Switzerland, 2007.

87. Liu, L.; Zhang, Y.; Jiao, Q.; Peng, D. Assessing photosynthetic light-use efficiency using a solar-induced chlorophyll fluorescence and photochemical reflectance index. Int. J. Remote Sens. 2013, 34, 4264-4280.

88. Meroni, M.; Rossini, M.; Guanter, L.; Alonso, L.; Rascher, U.; Colombo, R.; Moreno, J. Remote sensing of solar-induced chlorophyll fluorescence: Review of methods and applications. Remote Sens. Environ. 2009, 113, 2037-2051.

89. Mirdita, V.; Reif, J.C.; Ibraliu, A.; Melchinger, A.E.; Montes, J.M. Laser-induced fluorescence of maize canopy to determine biomass and chlorophyll concentration at early stages of plant growth. Albanian J. Agric. Sci. 2011, 10, 1-7.

90. Jones, H.G. Application of Thermal Imaging and Infrared Sensing in Plant Physiology and Ecophysiology. Adv. Bot. Res. 2004, 41, 107-163. 
91. Jiménez-Bello, M.; Ballester, C.; Castel, J.; Intrigliolo, D. Development and validation of an automatic thermal imaging process for assessing plant water status. Agric. Water Manag. 2011, 98, 1497-1504.

92. Leinonen, I.; Jones, H.G. Combining thermal and visible imagery for estimating canopy temperature and identifying plant stress. J. Exp. Bot. 2004, 55, 1423-1431.

93. Wang, X.; Yang, W.; Wheaton, A.; Cooley, N.; Moran, B. Automated canopy temperature estimation via infrared thermography: A first step towards automated plant water stress monitoring. Comput. Electron. Agric. 2010, 73, 74-83.

94. Jones, H.G. Use of infrared thermography for monitoring stomatal closure in the field: Application to grapevine. J. Exp. Bot. 2002, 53, 2249-2260.

95. Wang, X.; Yang Weiping, W.A.; Cooley, N.; Moran, B. Efficient registration of optical and IR images for automatic plant water stress assessment. Comput. Electron. Agric. 2010, 74, 230-237.

96. Leinonen, I.; Grant, O.M.; Tagliavia, C.P.P.; Chaves, M.M.; Jones, H.G. Estimating stomatal conductance with thermal imagery. Plant, Cell Environ. 2006, 29, 1508-1518.

97. Rebetzke, G.J.; Rattey, A.R.; Farquhar, G.D.; Richards, R.A.; Condon, A.T.G. Genomic regions for canopy temperature and their genetic association with stomatal conductance and grain yield in wheat. Funct. Plant Biol. 2013, 40, 14-33.

98. Saint Pierre, C.; Crossa, J.; Manes, Y.; Reynolds, M.P. Gene action of canopy temperature in bread wheat under diverse environments. TAG (Theor. Appl. Genet.; Theor. Angew. Genet.) 2010, 120, 1107-1117.

99. Romano, G.; Zia, S.; Spreer, W.; Cairns, J.; Araus, J.L.; MuǏLller, J. Rapid phenotyping of different maize varieties under drought stress by using thermal images. In Proceedings of the CIGR International Symposium on Sustainable Bioproduction-Water, Energy and Food, Tokyo, Japan, 19-23 September 2011; CIGR (Commission Internationale du Genie Rural); p. 22 B02.

100. Ballester, C.; Jiménez-Bello, M.; Castel, J.; Intrigliolo, D. Usefulness of thermography for plant water stress detection in citrus and persimmon trees. Agric. For. Meteorol. 2013, 168, 120-129.

101. Winterhalter, L.; Mistele, B.; Jampatong, S.; Schmidhalter, U. High throughput phenotyping of canopy water mass and canopy temperature in well-watered and drought stressed tropical maize hybrids in the vegetative stage. Eur. J. Agron. 2011, 35, 22-32.

102. André, F.; van Leeuwen, C.; Saussez, S.; van Durmen, R.; Bogaert, P.; Moghadas, D.; de Rességuier, L.; Delvaux, B.; Vereecken, H.; Lambot, S. High-resolution imaging of a vineyard in south of France using ground-penetrating radar, electromagnetic induction and electrical resistivity tomography. J. Appl. Geophys. 2012, 78, 113-122.

103. Noh, H.; Zhang, Q. Shadow effect on multi-spectral image for detection of nitrogen deficiency in corn. Comput. Electron. Agric. 2012, 83, 52-57.

104. Suárez, L.; Zarco-Tejada, P.; Berni, J.; González-Dugo, V.; Fereres, E. Modelling PRI for water stress detection using radiative transfer models. Remote Sens. Environ. 2009, 113, 730-744.

105. Malenovský, Z.; Mishra, K.B.; Zemek, F.; Rascher, U.; Nedbal, L. Scientific and technical challenges in remote sensing of plant canopy reflectance and fluorescence. J. Exp. Bot. 2009, 60, 2987-3004. 
106. Passioura, J.B. Grain Yield, Harvest Index, and Water Use of Wheat. J. Aust. Inst. Agric. Sci. 1977, 43, 117-120.

107. Monteith, J.L. Climate and the Efficiency of Crop Production in Britain. Philos. Trans. R. Soc. Lond. B Biol. Sci. 1977, 281, 277-294.

108. Reynolds, M.; Tuberosa, R. Translational research impacting on crop productivity in drought-prone environments. Curr. Opin. Plant Biol. 2008, 11, 171-179.

109. Richards, R.A.; Rebetzke, G.J.; Watt, M.; Condon, A.G.T.; Spielmeyer, W.; Dolferus, R. Breeding for improved water productivity in temperate cereals: phenotyping, quantitative trait loci, markers and the selection environment. Funct. Plant Biol. 2010, 37, 85-97.

110. Rebetzke, G.J.; Chenu, K.; Biddulph, B.; Moeller, C.; Deery, D.M.; Rattey, A.R.; Bennett, D.; Barrett-Lennard, E.G.; Mayer, J.E. A multisite managed environment facility for targeted trait and germplasm phenotyping. Funct. Plant Biol. 2013, 40, 1-13.

111. Sinclair, T.R.; Muchow, R.C. Radiation Use Efficiency. In Advances in Agronomy; Sparks, D.L., Ed.; Elsevier: Philadelphia, PA, USA, 1999; Volume 65, pp. 215-265.

112. Gastellu-Etchegorry, J.P.; Demarez, V.; Pinel, V.; Zagolski, F. Modeling radiative transfer in heterogeneous 3-D vegetation canopies. Remote Sens. Environ. 1996, 58, 131-156.

113. Gastellu-Etchegorry, J.P.; Martin, E.; Gascon, F. DART: A 3D model for simulating satellite images and studying surface radiation budget. Int. J. Remote Sens. 2004, 25, 73-96.

114. Brown, D.C. Close-range camera calibration. Photogramm. Eng. 1971, 37, 855-866.

115. Fryer, J.G.; Brown, D.C. Lens Distortion for Close-Range Photogrammetry. Photogramm. Eng. Remote Sens. 1986, 52, 51-58.

116. Trucco, E.; Verri, A. Introductory Techniques for 3-D Computer Vision; Prentice Hall PTR: Upper Saddle River, NJ, USA, 1998.

117. Sun, C. Fast Stereo Matching Using Rectangular Subregioning and 3D Maximum-Surface Techniques. Int. J. Comput. Vis. 2002, 47, 99-117.

118. Hartley, R.I.; Zisserman, A. Multiple View Geometry in Computer Vision, 2nd ed.; Cambridge University Press: Cambridge, United Kingdom 2004; ISBN: 0521540518.

119. Asner, G.P.; Martin, R.E. Airborne spectranomics: Mapping canopy chemical and taxonomic diversity in tropical forests. Front. Ecol. Environ. 2009, 7, 269-276.

(c) 2014 by the authors; licensee MDPI, Basel, Switzerland. This article is an open access article distributed under the terms and conditions of the Creative Commons Attribution license (http://creativecommons.org/licenses/by/3.0/). 